\title{
以菲二酰亚胺为发色团的苂光探针的研究进展
}

\author{
石岩*,a 于有伟 ${ }^{a}$ 薛 林 ${ }^{b}$ 王延风*,b \\ $\left({ }^{a}\right.$ 山西师范大学食品科学学院 临汾 041004) \\ $\left({ }^{b}\right.$ 山东省医学科学院药物研究所 济南 250062)
}

\begin{abstract}
摘要 近年来, 分子荧光探针以其高灵敏度、高选择性、专一性及设计的简便性等优点受到广泛的关注. 芢二酰亚胺 类(perylene tetracarboxylic diimide, PDI)衍生物具有良好的光热和化学稳定性、较高的苂光量子产率、较大的斯托克斯 位移以及易修饰性等优点，能够作为优良的苂光探针发色团. 芢四酸䣶结构本身具有强吸电子性，易被还原而不易被 氧化, 因此能够作为良好的电子受体. 但其自身结构容易发生 $\pi-\pi$ 堆积, 导致水溶性较差, 限制了其在生物领域里的大 范围应用. 通过研究人员的努力, 在 PDI 结构中引入亲水性基团改善了其水溶性. 根据被检测物种的种类对 PDI 类荧光 探针进行分类，详细介绍了近年来以 PDI 为发色团的苂光探针在离子检测、气体检测、生物分子检测等方面的研究进 展，并探讨探针的设计方法、荧光响应机制以及应用. 最后提出进一步构建新型 PDI 类衍生物分子荧光探针面临的挑 战和未来发展方向, 并对应用前景进行了展望.
\end{abstract}

关键词＼cjkstart菲二酰亚胺; 苂光探针; 离子检测; 气体检测; 生物分子检测

\section{Progress of Fluorescent Probes with Perylene Tetracarboxylic Diimide as Chromophore}

\author{
Shi, Yan ${ }^{*, a} \quad$ Yu, Youwei ${ }^{a} \quad$ Xue, Lin $^{b} \quad$ Wang, Yanfeng ${ }^{*, b}$ \\ ( ${ }^{a}$ Collge of Food Sciences, Shanxi Normal University, Linfen, Shanxi 041004) \\ ( ${ }^{b}$ Institute of Materia Medica Shandong Academy of Medical Sciences, Jinan 250062)
}

\begin{abstract}
In recent years, molecular fluorescent probes have attracted extensive attention due to their high sensitivity, high selectivity, specificity and simplicity of design. Perylene tetracarboxylic diimide derivatives (PDIs) are well known for their excellent photothermal stability, chemical stability, high fluorescence quantum yield, large stokes shift and easy modification. Therefore, they can be used as excellent fluorophores. PDI itself has strong electron-withdrawing group and easily to be reduced but it is hard to be oxidized. However, due to their inherent structure, the poor water solubility and aggregatable ablility limited their applications in biological fields. The water solubility of PDI was improved by introducing hydrophilic groups into the structure. Therefore, the PDIs with the unique advantages will have potential application values in the field of fluorescence probe and has been developed rapidly for the past few years. The development of PDI as a chromophore in fluorescent probe for the detection of ion, gas, biomolecules, etc. is systematically summarized. Meanwhile, the design of the probes, fluorescence response mechanism and application of the probe are also discussed. Finally, a novel type of PDI fluorescent probe is proposed. The challenge of construction of the PDIs and future development are also reviewed.
\end{abstract}

Keywords perylene tetracarboxylic diimide; fluorescent probe; ion-detection; gas detection; biomolecules detection

蕉二酰亚胺类衍生物(Perylene tetracarboxylic acid diimide derivatives, PDIs)(图 1)作为一种工业染料在二 十世纪初首次被报道 ${ }^{[1]}$. 除了作为工业染料, PDIs 由于 是一种近似于共平面共轭大 $\pi$ 键的稠环大分子, 它具有 独特的光化学和光物理性质: 热稳定性好, 苂光量子产
率高, 是良好的分子电子学和光学材料, 被广泛应用在 荧光传感材料、液晶材料、激光材料、有机场效应晶体 管及太阳能电池等领域. PDIs 具有较高的苂光量子产率 和光学稳定性, 已被证实是单分子光谱中最好的苂光 团, 并且苂光光谱峰的位置取决于菲二酰亚胺端位氮所

* Corresponding authors. E-mail: wyfshiwoya@126.com; shiyansdu@163.com Received June 13, 2019; revised July 5, 2019; published online July 24, 2019.

Project supported by the National Natural Science Foundation of China (No. 21305079).

国家自然科学基金(No. 21305079)资助项目. 
连取代基的性质及荘环湾位取代基团的性质 ${ }^{[2,3]}$. 大多 数 PDIs 不溶于水, 而溶于水的衍生物由于平面刚性结 构容易发生堆积, 因此经常被用来构建超分子结构, 包 括二聚体 ${ }^{[4]}$ 、低聚体 ${ }^{[5]}$ 、高分子 ${ }^{[6]}$ 和纳米结构 ${ }^{[7]}$, 而这些 结构很容易引起聚集并进而引起光物理性质的变化 ${ }^{[8]}$, 利用以上特性, PDIs 作为苂光发色团最终被设计成苂光 探针 ${ }^{[9 \sim 11]}$. 然而这种聚集导致菲四酸酐衍生物溶解性 差, 苂光量子产率降低 ${ }^{[12]}$, 大大制约了它在生物领域里 的应用. 可喜的是, 近年来一些新的修饰基团与 PDIs 连 接后, 改善了其在水中的溶解性, 同时保持了它传统的 优点，使得应用领域得到显著扩大.

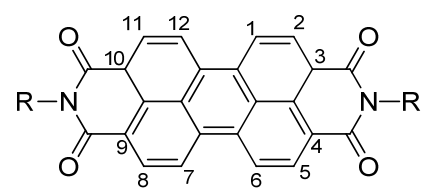

图 1 菲二酰亚胺(PDI)的分子结构图

Figure 1 Molecular structure of perylene diimide (PDI)

由于花二酰亚胺具有优良的光、热稳定性及良好的 化学稳定性, 同时湾位置及酰亚胺位置易于修饰, 且苂 光量子产率非常高, 因此近年来以菲二酰亚胺为荧光团 的苂光探针研究逐渐成为研究的热点. 本文主要综述了 其在苂光探针的研究进展.

\section{1 检测离子的探针}

\section{1 检测金属离子的荧光探针}

在具有重要的生物学意义的金属离子中, $\mathrm{Fe}^{3+}$ 是人 体中一种重要的微量元素, 它在血红素中作为氧的载体. 然而因为 $\mathrm{Fe}^{3+}$ 对脂类、蛋白质和其他细胞的促进作用, 过 量的 $\mathrm{Fe}^{3+}$ 是有害的, 因此实现对 $\mathrm{Fe}^{3+}$ 的快速检测是非常
重要的, 而苂光探针就是一种方便操作的检测方式.

2004 年, 张德清和朱道本课题组 ${ }^{[13]}$ 在荘二酰亚胺 的 1,7-位引入能够光致变色的螺吡喃分子, 从而形成复 合的 PDI 衍生物探针 1, 通过调解两者之间的光致电子 转移(Photoinduced Electron Transfer, PET, Eq. 1)过程进 而影响其苂光光谱的变化. 光谱以及电化学研究表明, 在基态时由于菲二酰亚胺与螺吡喃之间存在 PET 作用, 菲二酰亚胺的苂光几乎完全淬灭; 在紫外光、 $\mathrm{Fe}^{3+}$ 以及 质子共存时其荧光恢复，构筑了一个新型的三输入的 AND 逻辑门. 该结果为不同极性溶剂中 $\mathrm{Fe}^{3+}$ 存在时光 谱的研究提供了新的思路.

同样基于 PET 原理, 刘建勇课题组 ${ }^{[14]}$ 设计并合成 了探针 2 , 与 $\mathrm{Fe}^{3+}$ 作用前, 由于发生氮原子到苂光团的 PET 作用, 化合物的荧光淬灭; 当与 $\mathrm{Fe}^{3+}$ 结合以后, PET 作用受到禁止, 苂光恢复, 从而实现了对 $\mathrm{Fe}^{3+}$ 的检 测(Eq. 2).

2010 年, 李希友等 ${ }^{[15]}$ 设计合成了分别对 $\mathrm{Ni}^{2+}$ 和 $\mathrm{Fe}^{3+}$ 具有高选择性的苂光 “开-关”型探针分子 $\mathbf{3}$ 和 $\mathbf{4}$, 探 针将 PDIs 单元通过不同的连接桥和两个二-(2-皮考林) 胺基[di-(2-picolyl)amine, DPA]结合在一起, 与苯链接基 直接相连的氮原子发生向 PDIs 环的 PET 作用. DPA 在 探针分子中作为识别基团能够选择性地和不同金属离 子络合，两个探针溶液中分别加入上述两种金属离子 时, PET 作用受到限制, 使得荧光重新恢复. 通过选择 性实验可知, 探针分子 3 在干扰金属离子 $\mathrm{Na}^{+}, \mathrm{Cr}^{3+}$, $\mathrm{Mn}^{2+}, \mathrm{Fe}^{3+}, \mathrm{Co}^{2+}, \mathrm{Cu}^{2+}, \mathrm{Zn}^{2+}, \mathrm{Cd}^{2+}, \mathrm{Hg}^{2+}$ 和 $\mathrm{Pb}^{2+}$ 存在且 浓度为 $\mathrm{Ni}^{2+}$ 浓度的四倍时, 对 $\mathrm{Ni}^{2+}$ 仍具有良好的选择性 和灵敏度; 而探针分子 4 在干扰离子 $\mathrm{Na}^{+}, \mathrm{Cr}^{3+}, \mathrm{Mn}^{2+}$, $\mathrm{Co}^{2+}, \mathrm{Ni}^{2+}, \mathrm{Cu}^{2+}, \mathrm{Zn}^{2+}, \mathrm{Cd}^{2+}, \mathrm{Hg}^{2+}$ 和 $\mathrm{Pb}^{2+}$ 存在时对 $\mathrm{Fe}^{3+}$ 具有良好的选择性和灵敏度.

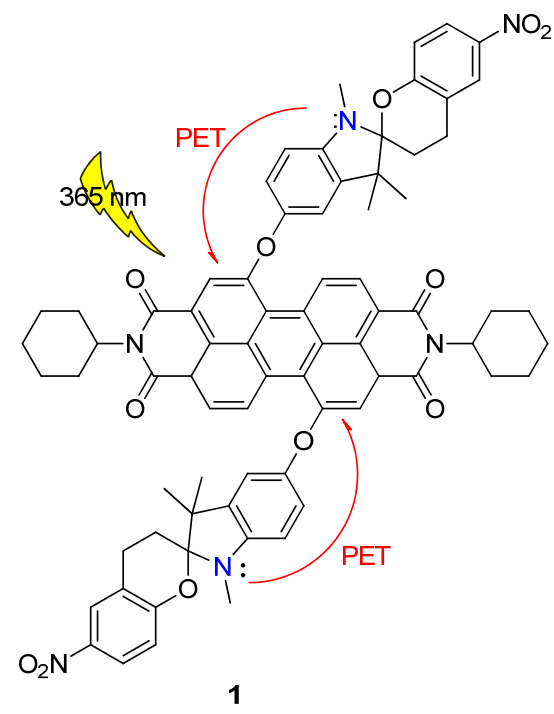

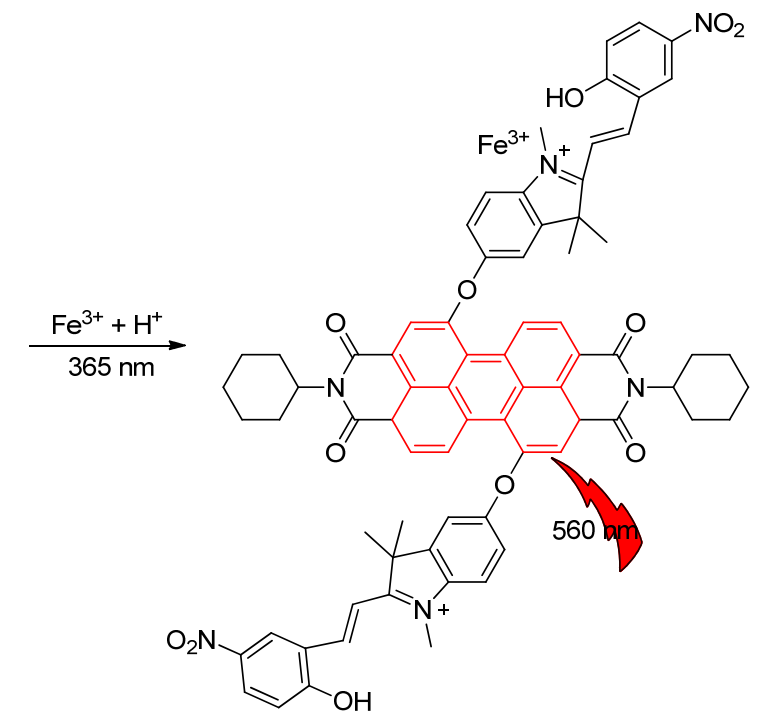


$\mathrm{R}$

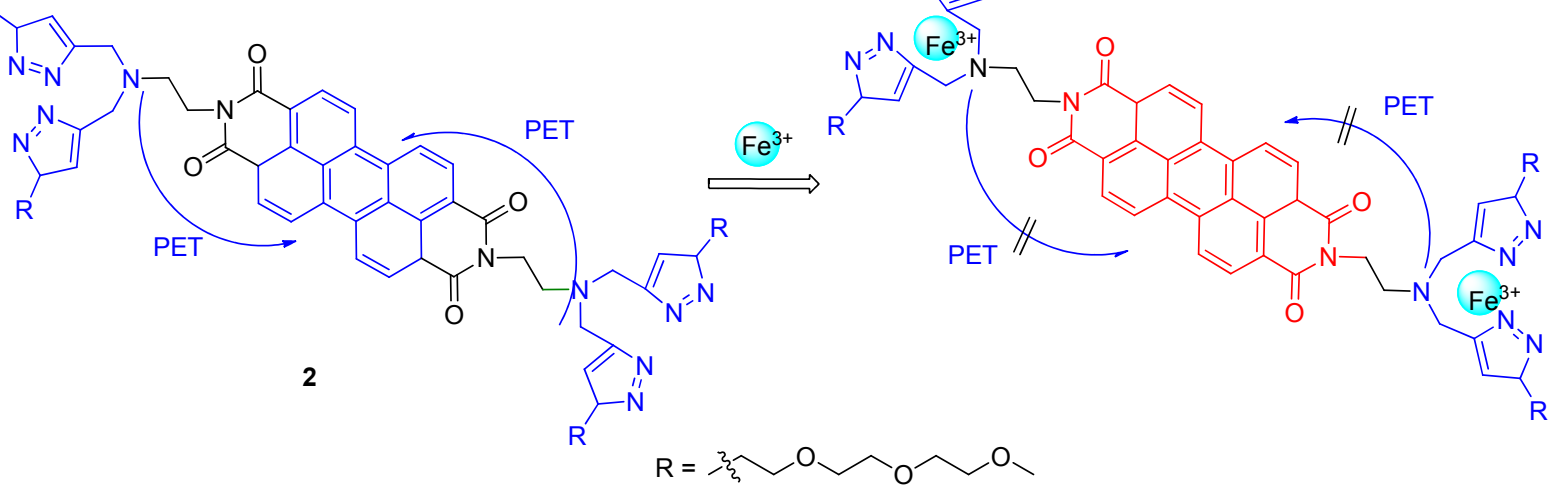
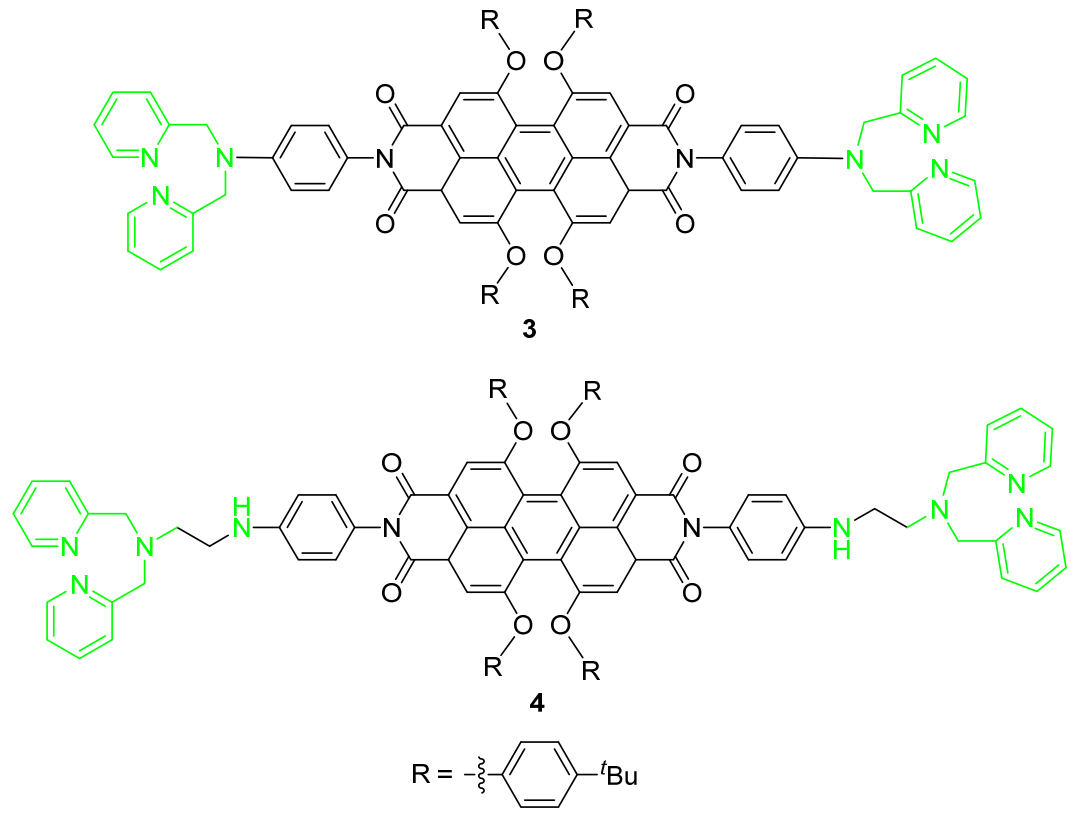

2015 年, 钱鹰课题组 ${ }^{[16]}$ 基于荧光共振能量转移 (Fluorescence Resonance Energy Transfer, FRET, Eq. 3)机 理设计合成了一种新型的菲二酰亚胺类苂光探针 $\mathbf{5}$, 探 针 5 将四个萗酰亚胺衍生物通过连接基团与菲二亚酰胺 相连, 在未与 $\mathrm{Fe}^{3+}$ 结合前, 以荎酰亚胺的吸收峰激发时, 探针发射的是其本身的发射峰, 说明没有能量转移. 与 $\mathrm{Fe}^{3+}$ 结合后, 以菜酰亚胺的吸收峰激发探针, 发射的是 菲二酰亚胺的发射峰, 说明发生了菜酰亚胺向菲二酰亚 胺的 FRET 作用. 该探针对 $\mathrm{Fe}^{3+}$ 有非常好的键合能力及 敏感性, 对 $\mathrm{H}^{+}$也有很好的识别作用.

2005 年, 李玉良课题组 ${ }^{[17]}$ 报道了以菲二酰亚胺为 荧光团并能够用于检测 $\mathrm{Cu}^{2+}$ 的荧光探针 6 . 与 $\mathrm{Cu}^{2+}$ 结合 前, 该探针通过弱的 $\mathrm{N} \cdot \mathrm{Au}$ 配位作用使菲二酰亚胺相 连的吡啶氮原子与金纳米离子结合, 由于金纳米粒子是 良好的淬灭试剂, 能够发生苂光团向金纳米粒子的能量 转移(Energy Transfer, ET), 从而导致菲二酰亚胺苂光淬 灭; 与 $\mathrm{Cu}^{2+}$ 结合后, 由于 $\mathrm{Cu}^{2+}$ 与 $\mathrm{N}$ 原子的配位作用更
强, 因此 $\mathrm{Cu}^{2+}$ 取代 $\mathrm{Au}$ 纳米粒子与吡啶配位, 阻断了 $\mathrm{ET}$ 作用的发生，使得菲二酰亚胺处于 $600 \mathrm{~nm}$ 处的荧光恢 复(Eq. 4). 该探针检测灵敏度高，检测下限为 $1 \mu \mathrm{mol}$ $\mathrm{L}^{-1}$ ，并且其他金属离子对 $\mathrm{Cu}^{2+}$ 的检测不产生干扰.

2012 年李春等 ${ }^{[18]}$ 通过在菲的酰亚胺位修饰甘氨酸 和天冬氨酸的二肽得到探针 7 , 该探针酰亚胺位具有两 个羧酸官能团. 这两个官能团能够与 $\mathrm{Cu}^{2+}$ 络合, 并使探 针 7 发生 $\mathrm{H}$-型聚集, 荧光淬灭. 当向探针 7 和 $\mathrm{Cu}^{2+}$ 的混 合物中加入焦磷酸盐(pyrophosphate, PPi)时, 由于探针 7 与 PPi 的络合作用强于与 $\mathrm{Cu}^{2+}$ 的络合作用，与 $\mathrm{Cu}^{2+}$ 配 位导致的聚集解聚，重新得到探针 7 的非聚集态，苂光 恢复. 这是 PDIs 首次在纯水溶液中用于 PPi 的荧光检 测. 次年朱守荣等 ${ }^{[19]}$ 将天冬氨酸直接修饰酰亚胺位得 到能检测 $\mathrm{Cu}^{2+}$ 的苂光探针 8. 该探针与 PDI-GlyAsp 类 似，同样能够在 $\mathrm{Cu}^{2+}$ 存在时，苂光发生淬灭，再加入三 磷酸腺苷(Adenosinetriphosphate, ATP), 苂光恢复. 

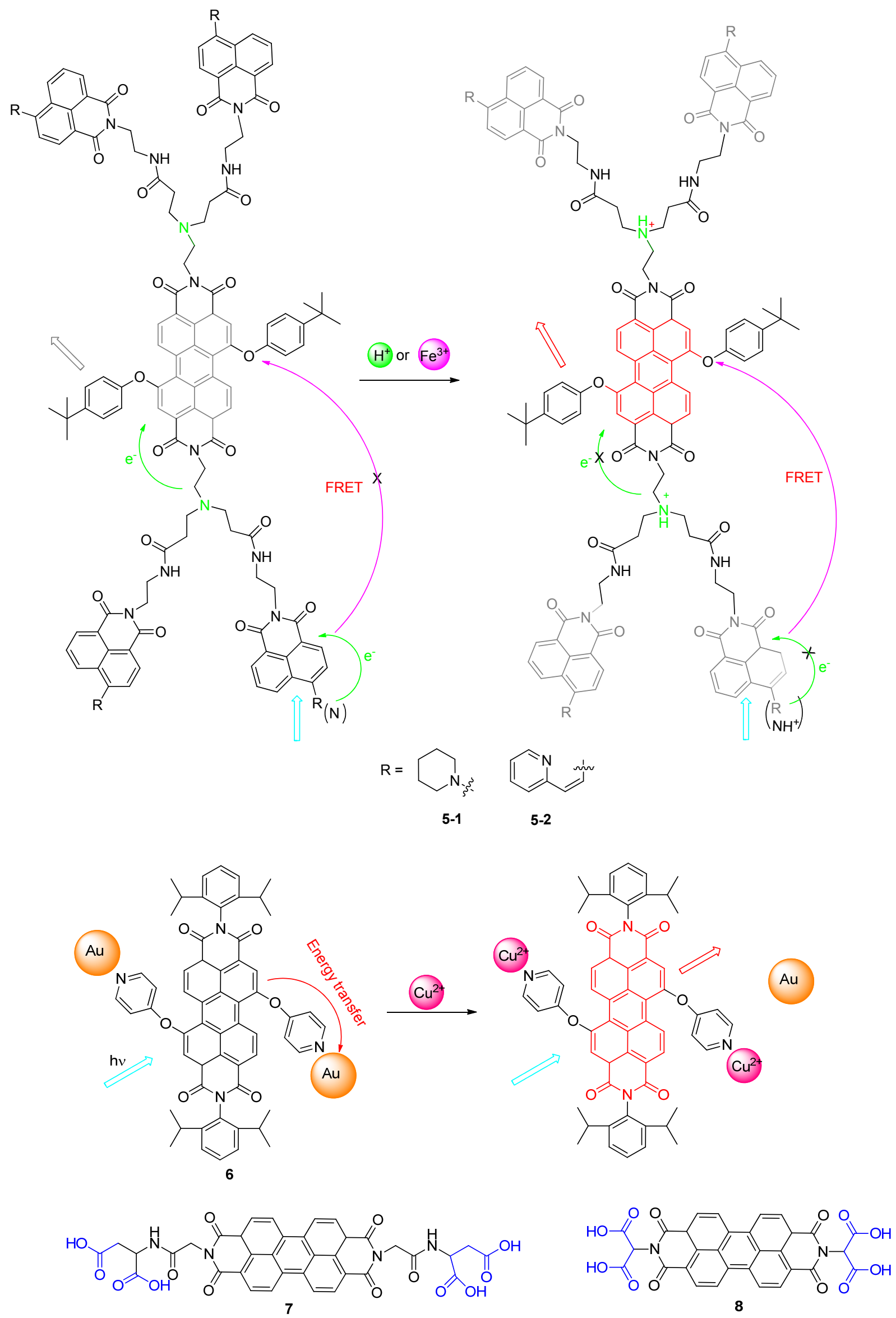
王利民等 ${ }^{[20]}$ 利用氨基对 $\mathrm{Cu}^{2+}$ 的络合能力, 在湾位 通过酰胺键修饰吡啶基团得到探针分子 9. 该探针分子 在水溶液中可以与 $\mathrm{Cu}^{2+}$ 络合形成 $2: 1$ 的配合物, 配合 物形成后由于 $\mathrm{Cu}^{2+}$ 的顺磁性以及探针 9 向 $\mathrm{Cu}^{2+}$ 的能量 转移作用, 探针的荧光发生猝灭(Eq. 5). 该探针在四氢 呋喃溶液中还可以结合 $\mathrm{F}^{-}$, 湾位氨基上的氢被 $\mathrm{F}^{-}$夺取, 导致探针的苂光淬灭. 该分子是首例以菲二酰亚胺为荧 光团的双功能探针.

付丽娜及其合作者 ${ }^{[21]}$ 通过在 PDIs 的湾位引入吸电 子基团, 在酰亚胺位置引入二甲基吡啶作为供电子基团 设计合成了探针分子 10 , 该探针分子结构的优化使其 在空气中具有更好的稳定性. 研究结果表明, $\mathrm{Cu}^{2+}$ 与 PDI 湾位的 $\mathrm{Cl}$ 原子发生了络合作用形成物质的量之比 $1: 2$ 、配位数为 4 的螯合物(Eq. 6). 发色团与金属离子 之间发生了 PET 效应，苂光猝灭.

录离子 $\left(\mathrm{Hg}^{2+}\right)$ 作为一种重金属污染物对环境和人体 都有很大危害. 近年来, 苂光探针在检测录离子方面的 研究不断取得进展, 检测极限越来越低, 探针的稳定性 也越来越高. 使用 PDIs 作为苂光基团的录离子探针在 保持苂光稳定性的同时, 检测极限不断降低并且专一性 也不断增强. PDIs 类的录离子探针一般使用氨类基团对 永离子进行络合, 从而引起紫外光谱和荧光光谱的变 化, 并且当菲二酰亚胺排列形成 $\mathrm{H}-$ 型聚集或 $\mathrm{J}$-型聚集时
会发生有效的苂光猝灭, 并且伴随着明显的吸收光谱变 化.

胸腺嘧啶 $(\mathrm{T})$ 是目前发现的与 $\mathrm{Hg}^{2}$ 结合最具选择性 的配体之一, 2008 年张玲等 ${ }^{[22]}$ 利用该特点在芢二酰亚胺 的酰亚胺位引入胸腺嘧啶作为 $\mathrm{Hg}^{2+}$ 结合位点设计合成 了 $\mathrm{Hg}^{2+}$ 苂光探针 11. 该化合物中的胸腺嘧啶配体( $\mathrm{T}$ ) 在 菲二酰亚胺末端与 $\mathrm{Hg}^{2+}$ 结合形成稳固的 $\mathrm{T}-\mathrm{Hg}^{2+}-\mathrm{T}$ 结构. 在没有 $\mathrm{Hg}^{2+}$ 的情况下，探针 $\mathbf{1 1}$ 发射强荧光; 加入 $\mathrm{Hg}^{2+}$ 后，分子间组成 “ $Z$ ” 字形结构, PDIs 之间由于 “ $\pi-\pi$ ” 相互作用形成聚集, 苂光猝灭. 该探针分子对 $\mathrm{Hg}^{2+}$ 具有 良好的选择性和敏感性，检测限最低可达 $5 \times 10^{-9} \mathrm{~mol} \cdot$ $\mathrm{L}^{-1}$ (甚至更低). 同样基于聚集原理, 以胸腺嘧啶作为结 合位点, 2010 年江云宝课题组 ${ }^{[23]}$ 设计合成了苂光探针 12. Scheme 1 显示了其作为 $\mathrm{Hg}^{2+}$ 探针的原理, 胸腺嘧啶 同样是在 PDIs 末端与 $\mathrm{Hg}^{2+}$ 结合形成稳固的 $\mathrm{T}-\mathrm{Hg}^{2+}-\mathrm{T}$ 结 构. 与探针 $\mathbf{1 1}$ 不同的是，该探针在与 $\mathrm{Hg}^{2+}$ 结合后，溶液 中的 PDIs 单体形成线型配合物, 芢环形成完全面对面 的 $\mathrm{H}$-型聚集，因此荧光显著淬灭. 而在半胱氨酸、高半 胱氨酸和谷胱甘肽的存在下, $\mathrm{H}-$ 型聚集体会发生解聚集, 荧光重新恢复. 而且, 因为 T-Hg-T 结构对 $\mathrm{Hg}^{2+}$ 极好的 线性选择性，其他离子的存在并不会对 $\mathrm{Hg}^{2+}$ 检测产生 干扰. 该探针对 $\mathrm{Hg}^{2+}$ 的检测限最低可达 $5 \mathrm{nmol} \cdot \mathrm{L}^{-1}$.

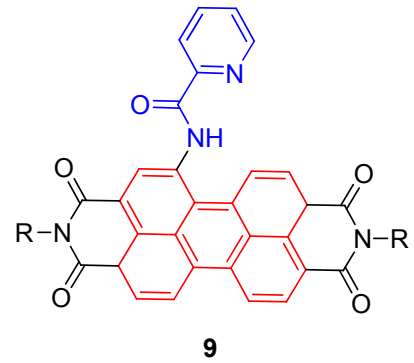

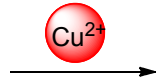

$\mathrm{R}=$

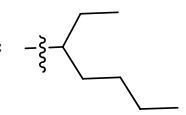

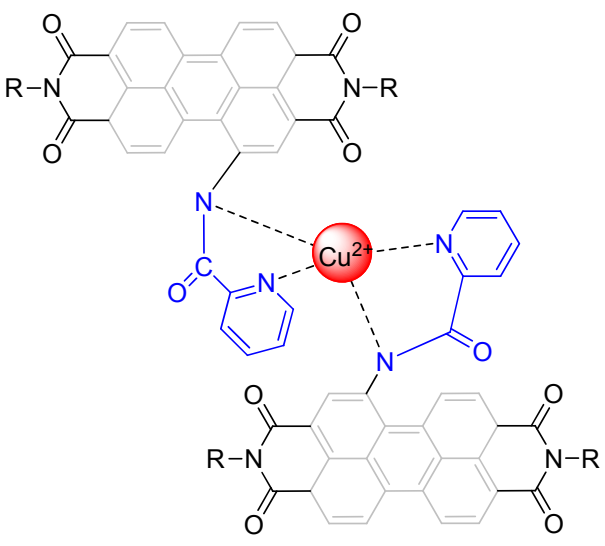

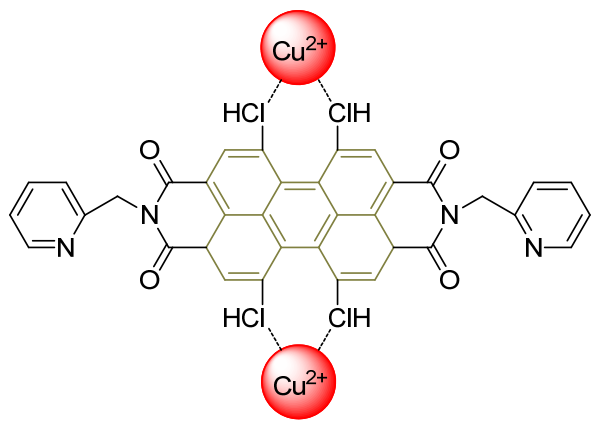




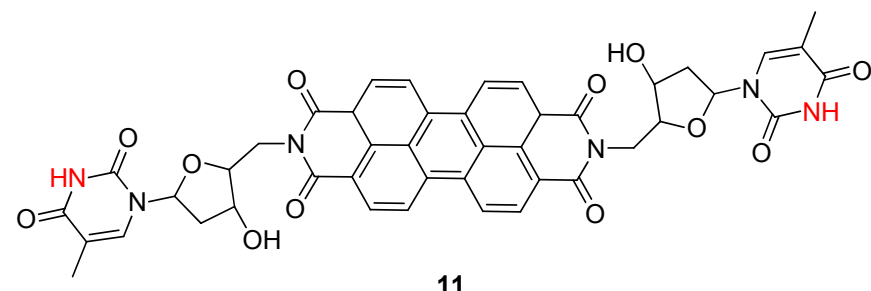

11

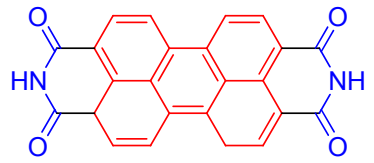

12<smiles>Cc1c[nH]c(=O)[nH]c1=O</smiles>

Thymine

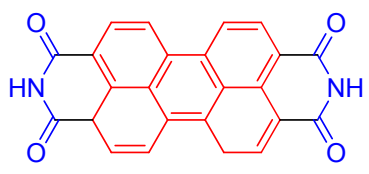

12
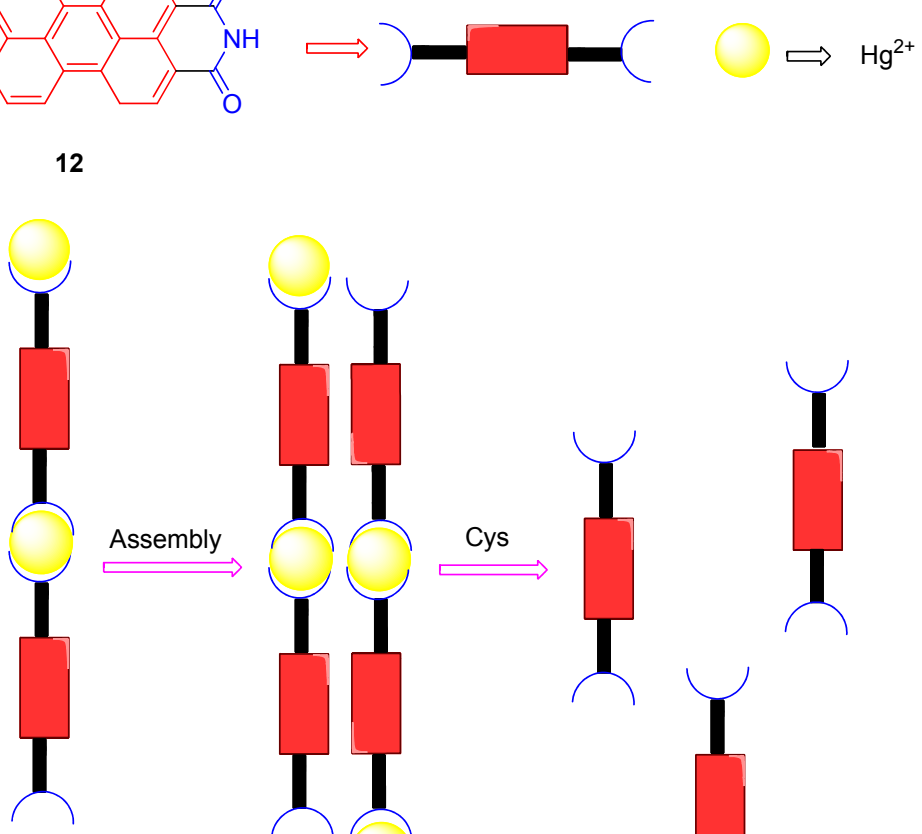

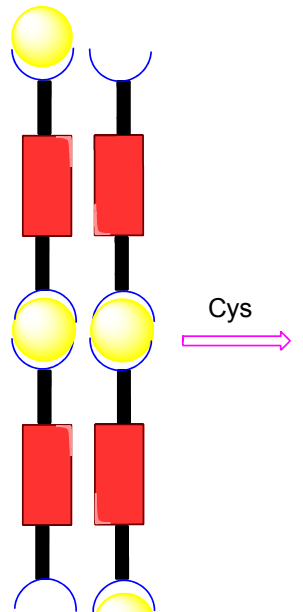

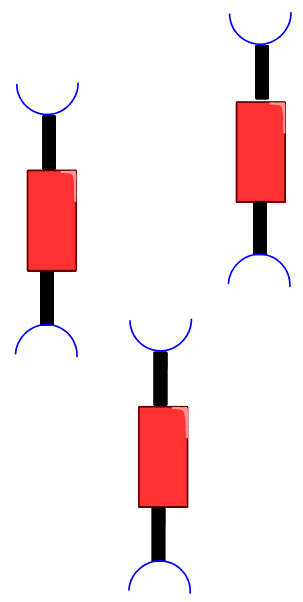

图式 $1 \mathrm{Hg}^{2+}$ 在 Cys 存在下诱导探针 12 聚集和聚集解离

Scheme 1 Scheme of $\mathrm{Hg}^{2+}$ induced aggregation of probe 12 and aggregate dissociation in the presence of cysteine

2014 年林宏洲课题组 ${ }^{[2]}$ 利用该原理设计合成了探

针 13, 探针 13 是在 PDIs 的湾位置引入对叔丁基苯酚, 而酰亚胺位置只用氨基对酸䣶位置进行保护形成酰亚 胺. $\mathrm{Hg}^{2+}$ 与两端的氨基发生络合作用, 并使得 PDI 两端 相连形成 J-型聚集体, 引起荧光淬灭和紫外光谱的红 移. 半胱氨酸中的硫原子对 $\mathrm{Hg}^{2+}$ 有更强的络合作用, 能 够从 PDIs- $\mathrm{Hg}^{2+}$ 复合物中夺取录离子, 使得 $\mathrm{J}$-型聚集解 离, PDIs 的荧光恢复. 在此过程中伴随着裸眼可见的颜 色变化. 此探针对 $\mathrm{Hg}^{2+}$ 和半胱氨酸的检测极限分别达 到 36.6 和 $91.3 \mathrm{nmol} \cdot \mathrm{L}^{-1}$. 更有意义的是该探针能够重复 使用八个周期, 进一步证实了探针 $-\mathrm{Hg}^{2}$ 解聚集的可能 性. 同年, 沈杰等 ${ }^{[25]}$ 利用该机理设计合成了在 PDI 湾位 置修饰了二硫缩醛的探针 14, 该探针在 PDI 湾位置引入 了四个带有二硫缩醛的苯酚基团后分子间聚集程度减 弱, 在 $629 \mathrm{~nm}$ 处发射出强烈的红光; 当该分子与 $\mathrm{Hg}^{2+}$ 结合后, 二硫缩醛结构转化为醛基, 化合物水溶性减弱,<smiles>[R1][Y10]([H])=Cc1ccc(C(C)(C)C)cc1</smiles>

13
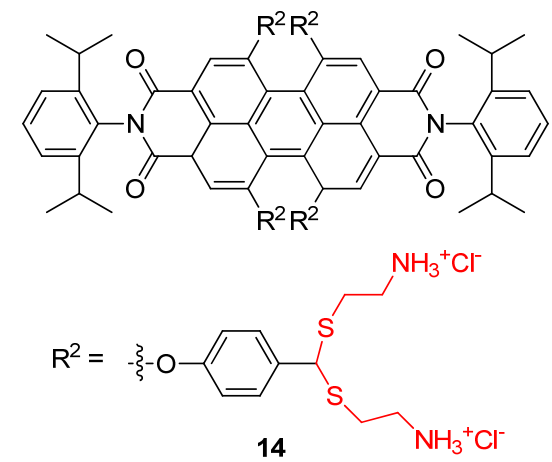
分子间堆积增加, 苂光发射减弱. 当颈基乙胺盐酸盐存 在时, 和 $\mathrm{Hg}^{2+}$ 结合后的探针分子苂光可以恢复到初始 状态, 说明探针 14 可以被重复使用. 该探针对 $\mathrm{Hg}^{2+}$ 具 有十分灵敏的响应性, 同时本身的正电荷结构可以作为 DNA 的载体.

上述的苂光探针均对 $\mathrm{Hg}^{2+}$ 具有良好的选择性和灵 敏度, 但是由于在水溶液中溶解度太低, 只能在 $\mathrm{N}, \mathrm{N}-$ 二 甲基酰胺(DMF) $-\mathrm{H}_{2} \mathrm{O}$ 的混合溶液中使用, 这就限制了 探针的实际应用. 同样基于聚集导致荧光猝灭机理, 韩 爱霞等 ${ }^{[26]}$ 设计合成了一种水溶性录离子识别探针 15 . 该探针在水溶液中与 $\mathrm{Hg}^{2+}$ 作用能发生聚集, 导致荧光 猝灭，且不受其他金属离子的影响，其良好的水溶性实 现了对水溶液中 $\mathrm{Hg}^{2+}$ 的实时测量, 简化了环境中录离 子监测的手段与方法.

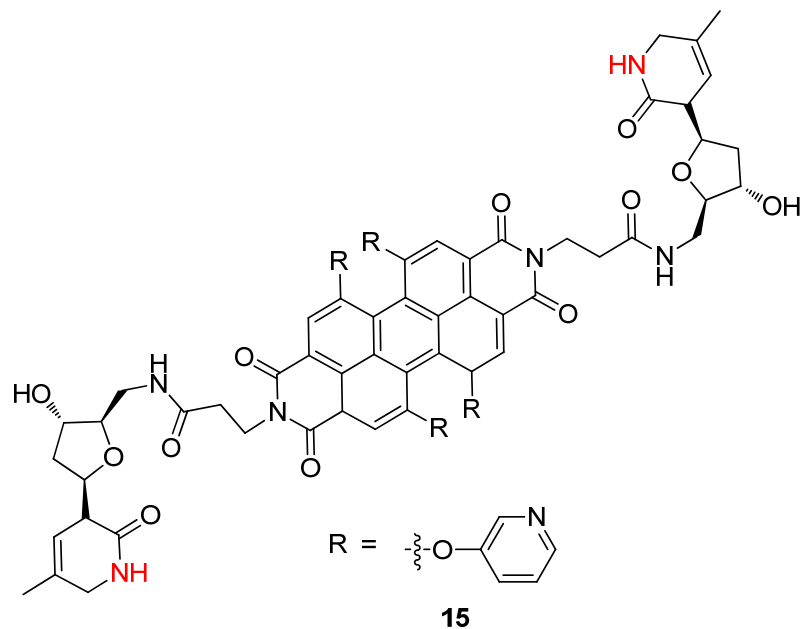

除基于聚集-解聚设计探针之外, 基于其他作用机 理的探针也备受关注. 2015 年, Erdemir 课题组 ${ }^{[27]}$ 基于 PET 机理设计合成了探针 16, 该探针在 PDI 的酰亚胺位 通过三(2-氨基乙基)胺连接噻吩基团, 在没有结合 $\mathrm{Hg}^{2+}$ 前, 发生三(2-氨基乙基)胺上的 $\mathrm{N}$ 至萠环的 PET 作用, 从而导致化合物的苂光强度非常低; 加入 $\mathrm{Hg}^{2+}$ 后发生 三(2-氨基乙基)胺上的四个 $\mathrm{N}$ 原子与 $\mathrm{Hg}^{2+}$ 配位，阻碍了 PET 作用的发生, 从而使得倸环的荧光恢复 (Eq. 7). 该 探针对录离子有高的选择性和灵敏性, 并且响应快速.

2015 年该课题组 ${ }^{[28]}$ 将上述探针中的噻吩基团换成 杯状[4]芳烃单元(CX[4]), 得到同样基于 PET 机理的能 够对 $\mathrm{Hg}^{2+}$ 进行 Turn-on 型检测的探针 17. PB-CX[4]对录 离子的检测具有更高的专一性, 检测极限进一步降低达 到 $5.56 \times 10^{-7} \mathrm{~mol} \cdot \mathrm{L}^{-1}$, 并且该探针被成功应用于细胞 内 $\mathrm{Hg}^{2+}$ 的检测.

成义祥课题组 ${ }^{[29]}$ 报道了一个基于 PDI 弯位修饰的 聚合物“turn-on”型探针分子 18. 在一个重复单元内, 化 合物的端位和湾位同时与 $\mathrm{Hg}^{2+}$ 络合, 与 $\mathrm{Hg}^{2+}$ 结合前,
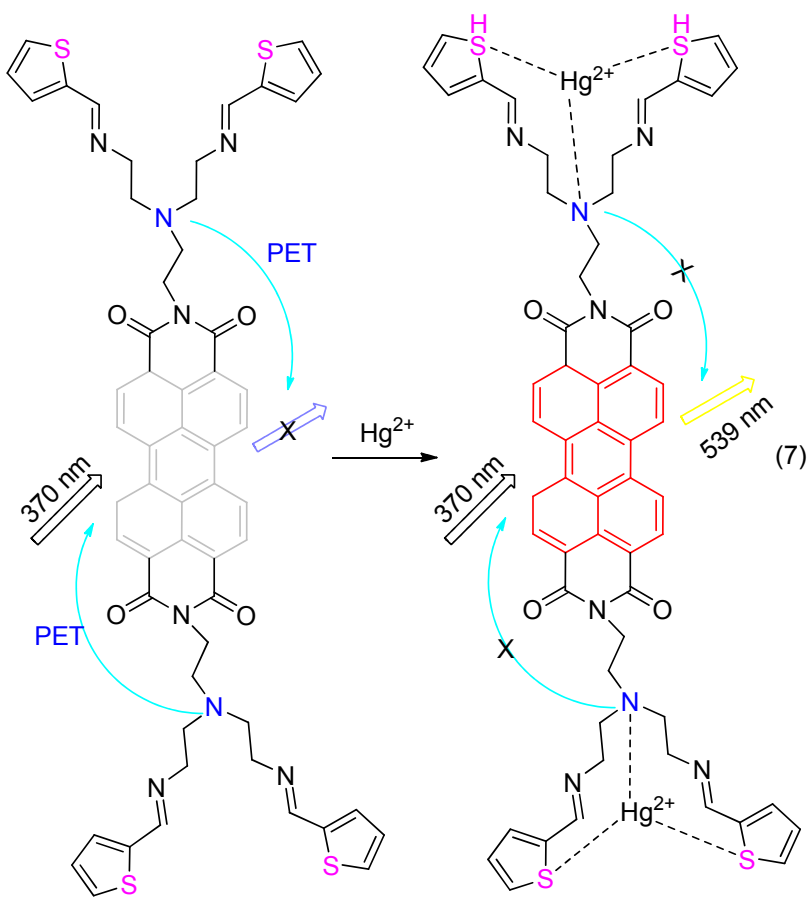

16

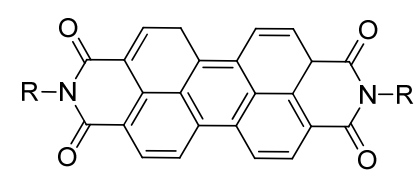

17

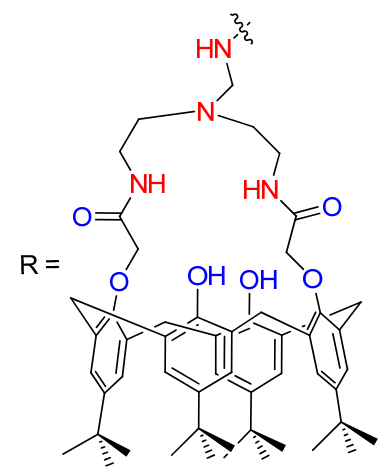

由于分子内电荷转移(Intramolecular charge transfer, ICT)作用, 化合物显示出暗红色的荧光, 而与 $\mathrm{Hg}^{2+}$ 结合 后，ICT 作用被禁止，此时显示出明亮的黄色苂光(Eq. 8). 同时化合物对 $\mathrm{Hg}^{2+}$ 显示了较高的选择性识别能力和 较低的检测限.

除 $\mathrm{Hg}^{2+}$ 外，铅 $(\mathrm{Pb})$ 是另外一种常见的环境和工业污 染物，少量的铅就会导致人体特别是儿童的肾脏疾病以 及抑制脑部发育. 因此, 发展一种快速有效并且能够灵 敏地检测铅的方法是环境科学及生命科学共同关注的 领域.

与 $\mathrm{Hg}^{2+}$ 探针设计思路类似, $\mathrm{Pb}^{2+}$ 探针也主要基于聚 集一解聚机理设计. 谢军课题组 ${ }^{[30]}$ 设计并合成了探针 19, 该探针将带有正电荷的化合物与核酸探针结合形成聚 集体，此时探针不具有苂光，当与 $\mathrm{Pb}^{2+}$ 结合后，核酸探 针与带正电荷的化合物分离, 带有正电荷的化合物由于 正电荷之间的斥力作用表现出有良好的单体荧光，也就 


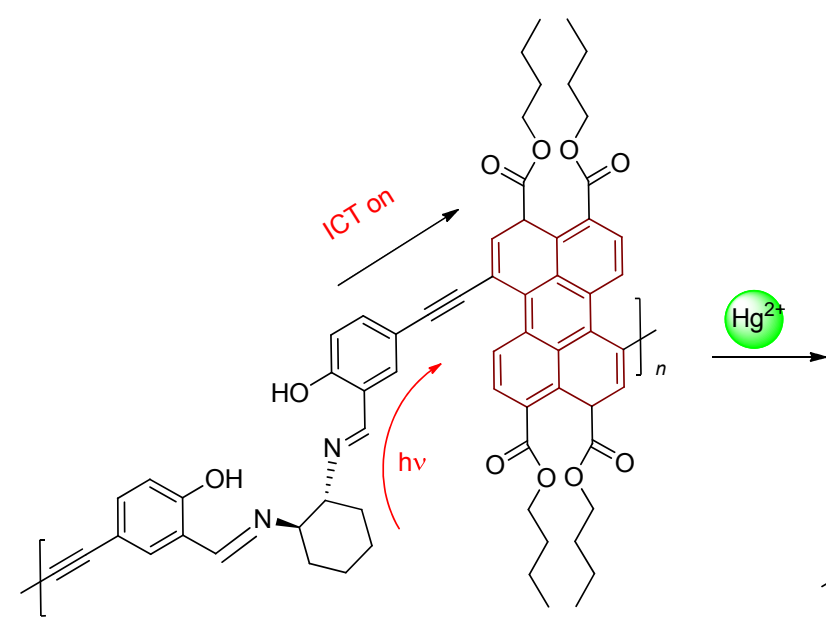

18

是说此时荧光恢复. 该探针对 $\mathrm{Pb}^{2+}$ 具有很高的选择性及 敏感性，检测限低至 $5.0 \mathrm{nmol} \cdot \mathrm{L}^{-1}$. 此外，该探针还能够 用于检测尿液和油漆样品中的 $\mathrm{Pb}^{2+}$. 兰静波等 ${ }^{[31]}$ 在菲 环的酰亚胺位置引入 $1,4,7,10$-四氮杂环十二烷合成了探 针 20 , 没有 $\mathrm{Pb}^{2+}$ 存在时, 由于芢环间的相互 $\pi-\pi$ 作用, 分子间发生聚集, 苂光消失; 与 $\mathrm{Pb}^{2+}$ 结合后, 由于正电 荷之间的斥力聚集作用被打破，重新恢复到单体状态， 荧光恢复. 该探针具有良好的选择性, 并且能够在生理 $\mathrm{pH}$ 条件下用于细胞内 $\mathrm{Pb}^{2+}$ 检测及成像.
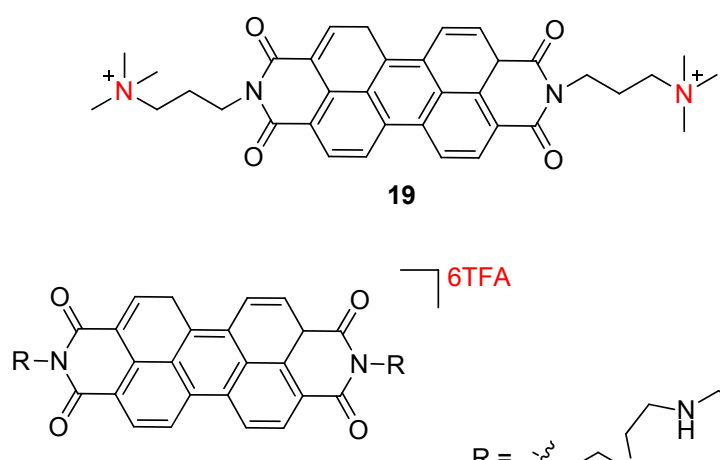

$20 a$

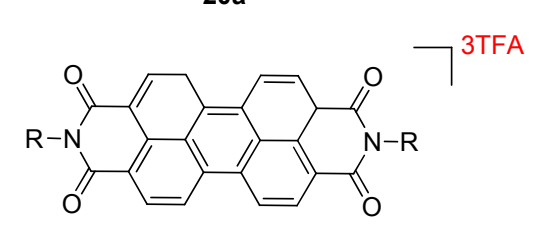

$20 b$

钯 $(\mathrm{Pd})$ 可以在体内积累，与蛋白质等生物大分子结 合, 导致 DNA 降解和多种细胞生理过程的紊乱. 建议 的膳食中 $\mathrm{Pd}$ 的最大摄入量为每人每天少于 $15 \mathrm{mg}$, 其在 药物中的阈值为 $5 \sim 10 \mathrm{mg} / \mathrm{L}$. 因此, 有必要开发高选择 性、高灵敏度的苂光探针用以快速检测生活系统和自然 环境中钯的存在及含量. 李希友课题组 ${ }^{[32]}$ 通过不同连

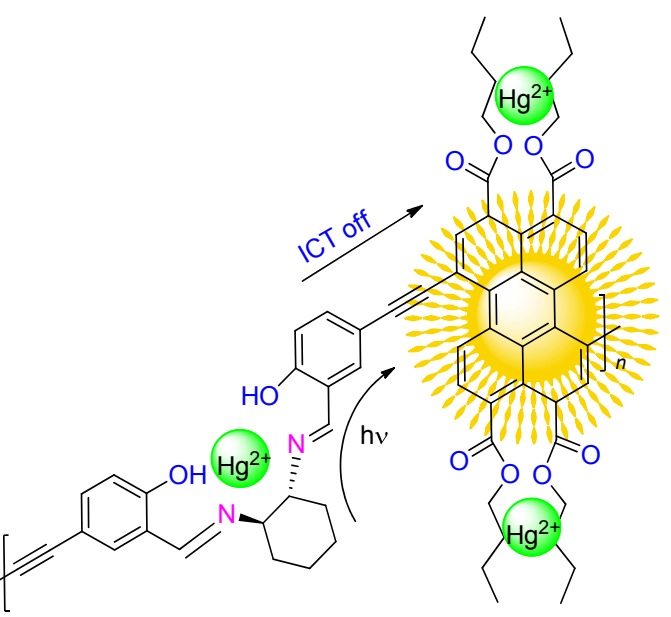

(8)
接基团将二甲基吡啶胺与菲二酰亚胺相连，设计合成了 一系列化合物，由于二甲基吡啶胺中的氨基氮原子发生 向菲二酰亚胺的 PET 作用, 因此探针分子 21 未与 $\mathrm{Pd}^{2+}$ 结合前几乎没有苂光; 与 $\mathrm{Pd}^{2+}$ 结合后, PET 作用被禁止, 菲二酰亚胺的荧光恢复，苂光颜色变化肉眼可见. 该探 针分子具有高度选择性及敏感性，检测限低至 7.32 $\mathrm{nmol} \cdot \mathrm{L}^{-1}$. 干扰实验显示在溶液中同时存在 $\mathrm{Ni}^{2+}, \mathrm{Fe}^{3+}$ 和 $\mathrm{Pd}^{2+}$ 的情况下, 探针 21 依然对 $\mathrm{Pd}^{2+}$ 具有很高的选择 性.

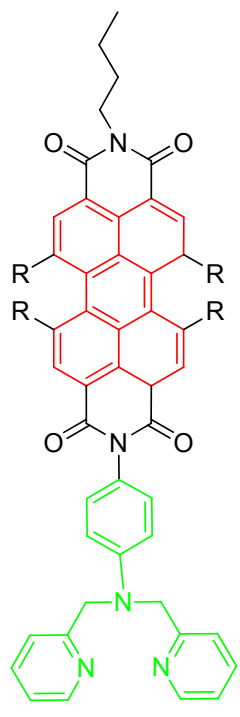

21a

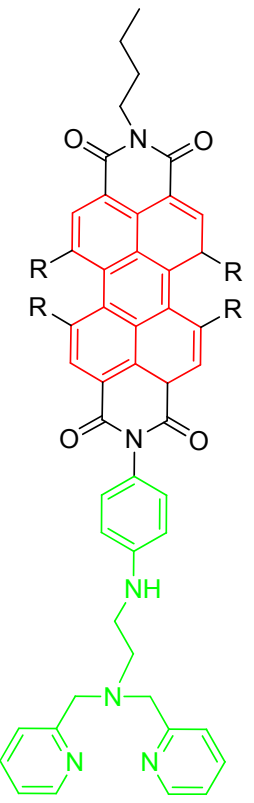

21b

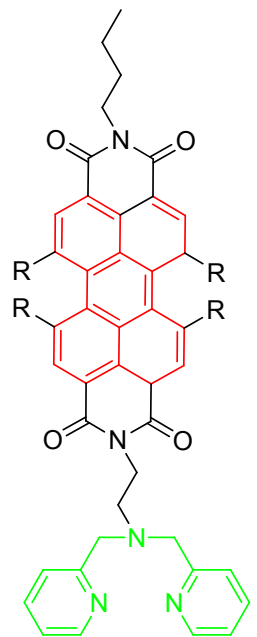

21c

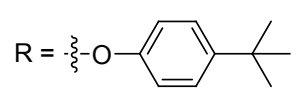

2013 年王利民课题组 ${ }^{[33]}$ 设计合成了探针 22, 与 $\mathrm{Pd}^{0}$ 结合后, 湾位置引入的烯丙酯基团发生水解, 吸收光谱 红移且荧光猝灭. 该探针分子对 $\mathrm{Pd}^{0}$ 具有良好的选择性 
和敏感性. 几年后, Kumar 课题组 ${ }^{[34,35]}$ 在此基础上进行 简化，设计合成了探针分子 23 和 24 . 探针分子 24 在不 同的溶剂中自组装成不同形貌的聚集体, 在 $\mathrm{Pd}^{0}$ 存在时 发生聚集体形貌变化的同时伴随着光谱的变化, 随着 $\mathrm{Pd}^{0}$ 浓度的增加吸收光谱呈现比率型变化而荧光光谱逐 渐猝灭 (Scheme 2). 该探针可以用来检测环境和药物中 的 $\mathrm{Pd}^{0}$ 以及尿液中 $\mathrm{Pd}^{2+}$, 且因为其低细胞毒性而被成功 地用于活体 HeLa 细胞内的 $\mathrm{Pd}^{0}$ 成像.

铝 $\left(\mathrm{Al}^{3+}\right)$ 是常见的金属, 被广泛地应用在现代生活 中, 已经被证实在环境方面对人体健康有害, 比如临床 发现过量的铝与阿尔茨海默症、关岛帕金森氏疾呆综合 症等疾病有关，这些病症被称为 “铝脑病”。2014 年,

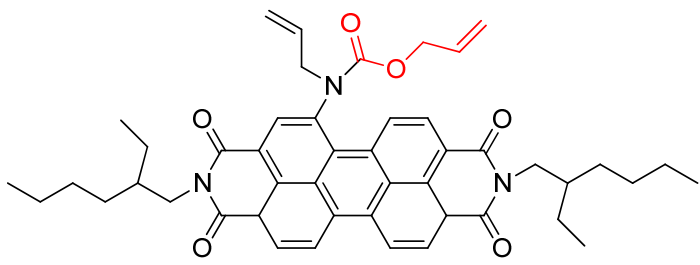

22<smiles></smiles>

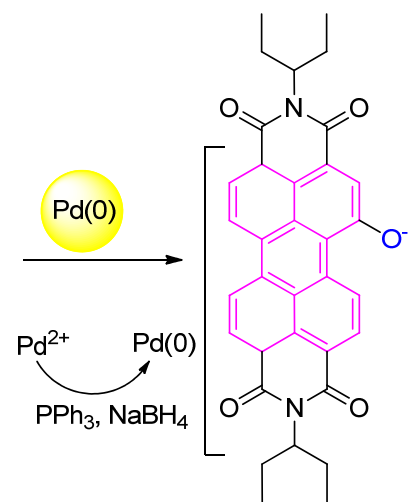

Malkondu ${ }^{[36]}$ 基于 PET 基理设计合成了能够识别 $\mathrm{Al}^{3+}$ 的 “turn-on” 型苂光探针 25 , 该探针在与 $\mathrm{Al}^{3+}$ 结合前几 乎没有苂光, 与 $\mathrm{Al}^{3+}$ 结合后苂光增强约 110 倍, 并且在 紫外灯下有肉眼可见的颜色变化(无色到亮黄色), 具有 极高的选择性和灵敏度.

除上述离子探针外, 上官棣华课题组 ${ }^{[37]}$ 在酰亚胺 位引入双(2-吡啶基甲基)胺，得到探针 26. 该化合物在 $\mathrm{pH}$ 大于 6 时发生端位氮原子向菲环的 PET 作用, 因此 表现出非常弱的荧光; 而在 $\mathrm{pH}$ 分别为 $6 \sim 7$ 和 9 时能够 与 $\mathrm{Zn}^{2+}$ 和 $\mathrm{Cd}^{2+}$ 络合, 均阻断了 PET 作用, 苂光恢复. 因 此, 该化合物在 $\mathrm{pH}=6$ 时可实现对 $\mathrm{Zn}^{2+}$ 的检测, 而在 $\mathrm{pH}=9$ 时, 可实现对 $\mathrm{Cd}^{2+}$ 的检测.

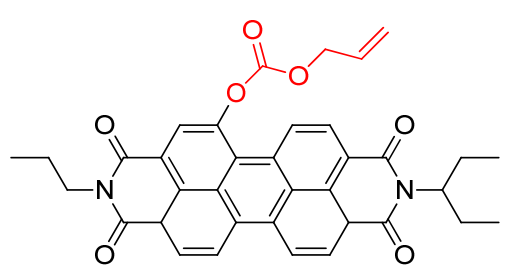

23

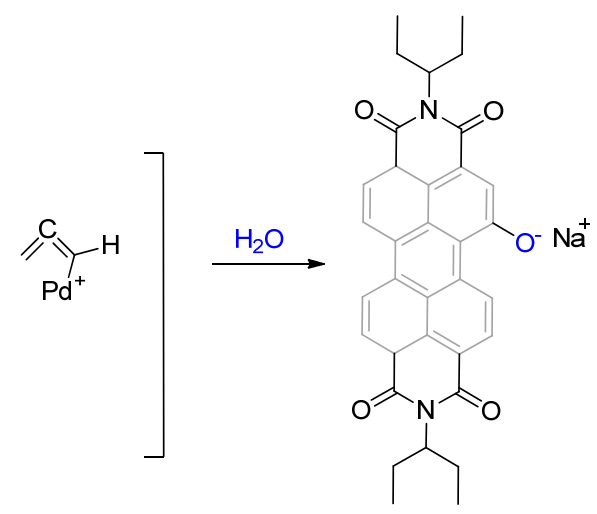

图式 2 探针分子 24 检测 $\operatorname{Pd}(0)$ 的识别机理

Scheme 2 Detection mechanism of $\operatorname{Pd}(0)$ by probe molecule 24<smiles></smiles>

25<smiles></smiles> 
综上所述，在设计用于检测金属离子的 PDIs 类荧光 探针时, 常用以下几类机理. 第一种是 PET 机理, 在未与 金属离子结合前由于发生氮原子、氧原子等杂原子上的 孤对电子向菲环的 PET 过程, 苂光猝灭; 当与被测金属 离子结合后, 杂原子上的孤对电子与金属离子络合, 阻 碍了该 PET 过程的发生, 苂光恢复. 常用该类机理设计 “开一关” 型苂光探针. 第二种是 ICT 机理, 即通过共轭链 (比如参键)将识别基团与菲环连接后, 形成 $\pi-\pi$ 共轭体系, 与金属离子结合前后紫外及苂光光谱都可能发生明显的 蓝移或红移, 表现为明显的比率型特点. 第三种则是利 用 “聚集一解聚” 机理, 菲环由于其自身的结构, 容易在 溶液中形成 $\mathrm{H}$-或 $\mathrm{J}$-型聚集体, 表现为荧光猝灭; 当金属 离子与 PDIs 探针分子的端位氮原子通过静电作用力结合 后, 会使得聚集体发生解聚, 表现为荧光恢复, 采离子苂 光探针大多利用该机理设计. 第四种是 FRET 机理, 探针 分子与待检测金属离子结合前后，同一激发波长激发时， 发射光谱发生明显的改变, 该类机理也是设计比率型探 针的最常见的机理之一(Scheme 3).

\section{$1.2 \mathrm{pH}$ 值的检测}

$\mathrm{pH}$ 是生物、化学和农业等领域中一个重要而普遍
的指标. 环境中 $\mathrm{pH}$ 值的检测直接关系到人们的日常生 活和身体健康, 同时环境水体中 $\mathrm{pH}$ 的变化还关系到水 体中动植物的生存和生长. 细胞内 $\mathrm{pH}$ 值在离子转运、 肌肉收缩、多药耐药、钙调节、细胞生长和调亡等细胞 事件中起着重要作用, 因此 $\mathrm{pH}$ 类探针受到人们越来越 多的关注 ${ }^{[38 \sim 42]}$. 2011 年, Chang 课题组 ${ }^{[43]}$ 报道了一个哌 嗪-9 位取代菲二酰亚胺的 $\mathrm{pH}$ 苂光探针分子 27 . 该化合 物 9-位哌嗪上的两个氮原子及酰亚胺相连的氮原子均 可以与氢质子结合(Scheme 4). 在酸性条件下 $491 \mathrm{~nm}$ 激 发时, 出现 585 和 $695 \mathrm{~nm}$ 两个峰, 经过验证, $585 \mathrm{~nm}$ 处 为菲环本体峰, 而 $695 \mathrm{~nm}$ 处为 9-位氨基氮原子电荷转 移激发态峰, 通过调节 $\mathrm{pH}$ 值, 化合物上的氮原子分步 与质子结合从而改变其溶液苂光性质. 此外，探针分子 还具有比率检测双链 DNA 的作用. 同样基于哌嗪与质 子结合改变化合物荧光性质的原理, 2013 年 Borisov 课 题组 ${ }^{[44]}$ 设计合成了探针 $\mathbf{2 8}$, 该探针在湾位引入哌嗪基 团，未与质子结合之前，由于发生哌嗪氮原子向荘环的 PET 作用, 因此苂光很弱; 当与质子结合后, PET 作用 禁止，苂光恢复(Scheme 4). 在此基础上，该课题组还 通过共价键连接交联聚乙烯合成新型近红外 $\mathrm{pH}$ 荧光

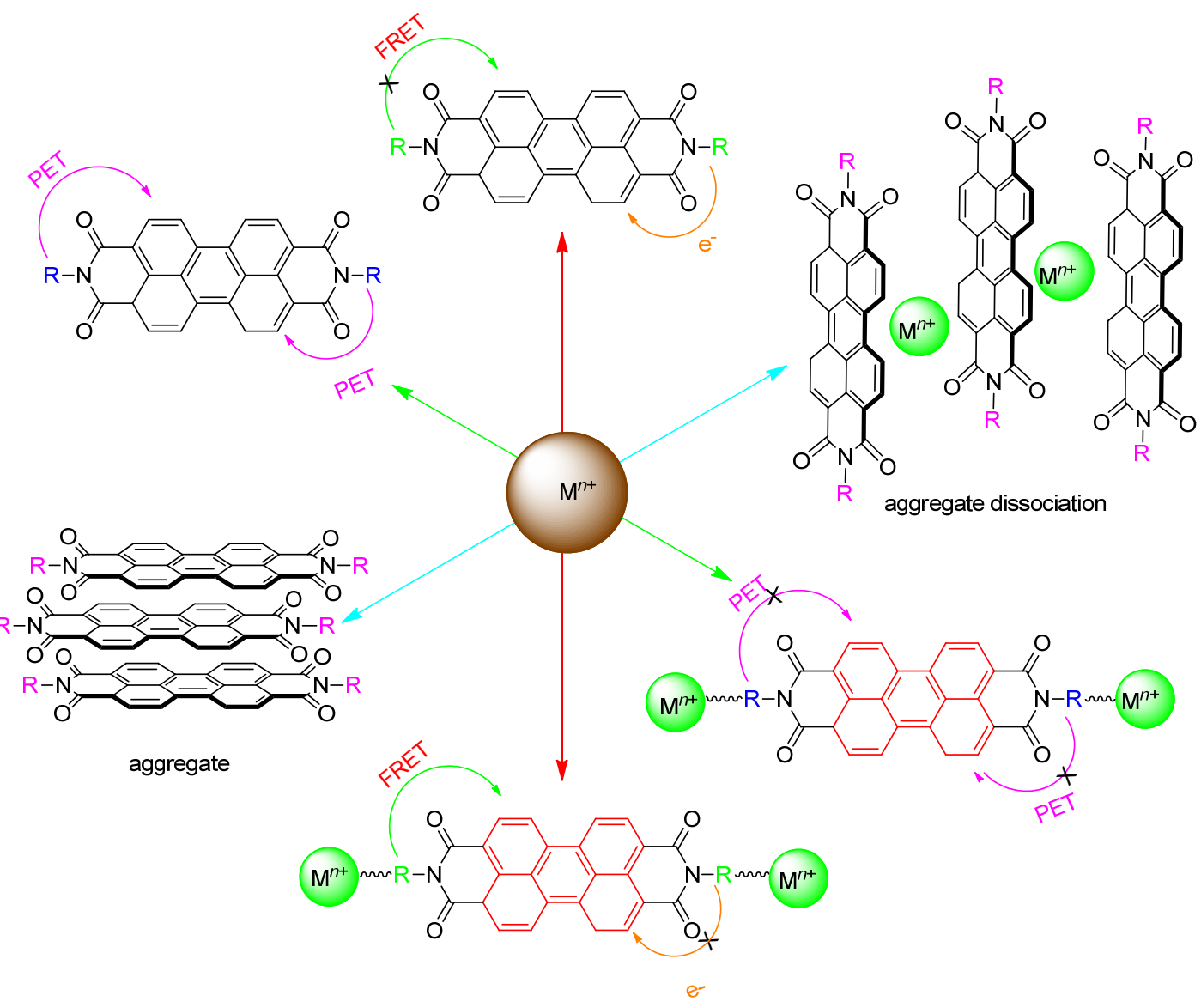

图式 3 调控荧光机理图

Scheme 3 Mechanism of adjusting and controlling of fluorescence 

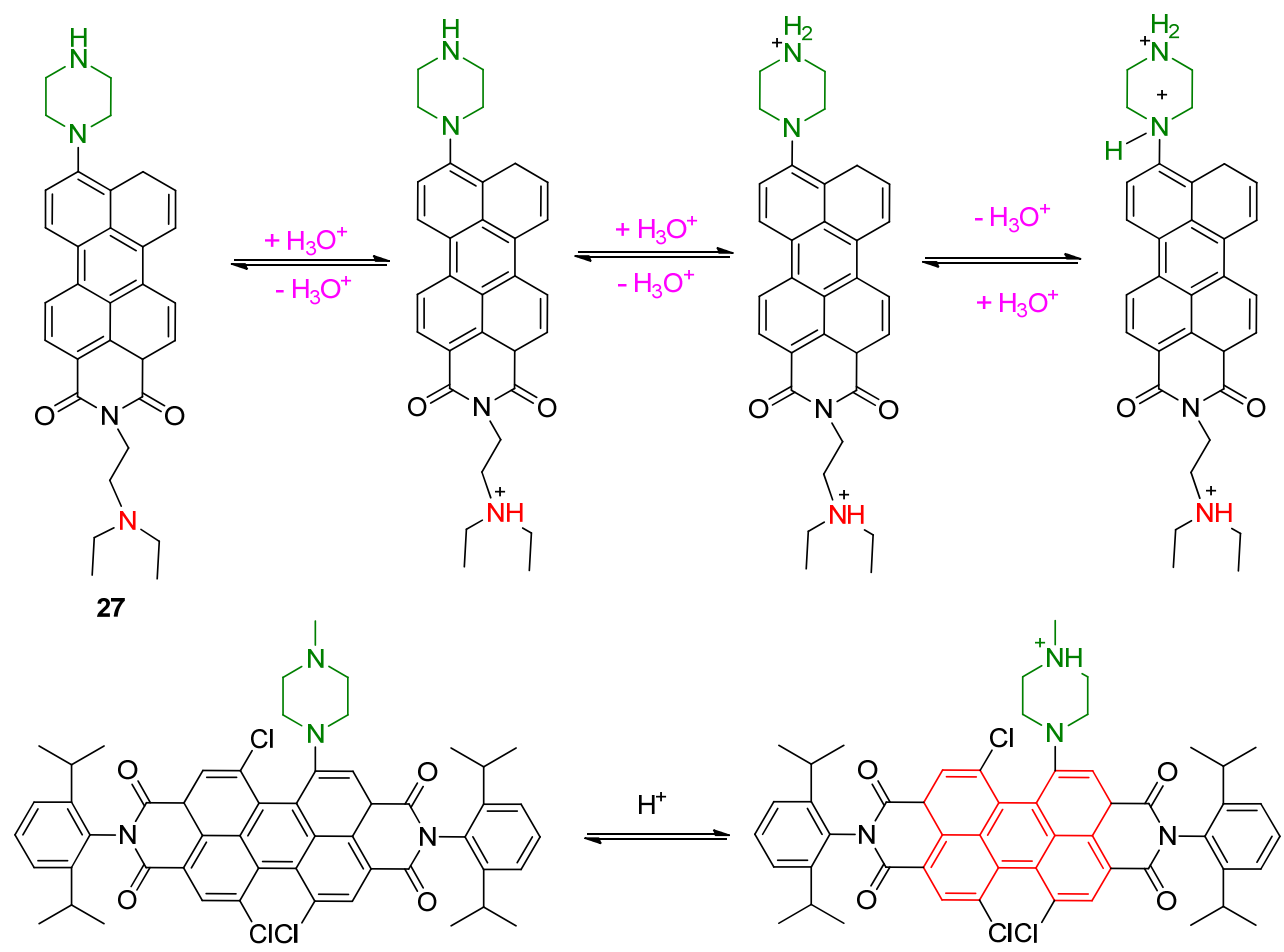

28

图式 4 探针分子 $\mathbf{2 4}$ 检测 $\mathrm{H}^{+}$的识别机理

Scheme 4 Recognition mechanism of probe molecular $\mathbf{2 4}$ for $\mathrm{H}^{+}$

探针. 此类探针苂光发射均在近红外光谱范围 $\left(\lambda_{\text {max }}=\right.$ $735 \mathrm{~nm}$ ), 有较大的斯托克斯位移 (>90 nm), 可用于生 物技术中 $\mathrm{pH}$ 值的检测.

为了比较氨基和酚氧基取代对化合物在 $\mathrm{pH}$ 检测时 的影响, 该课题组 ${ }^{[45]}$ 又设计合成了一系列不同位置不 同基团取代的探针 29. 通过实验证实利用酚基可以合

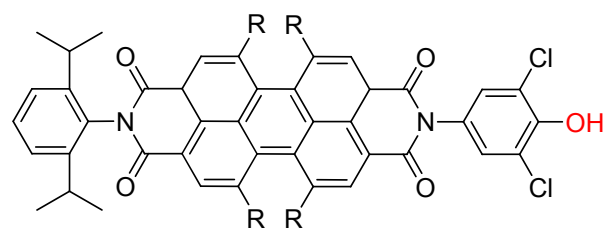

29a

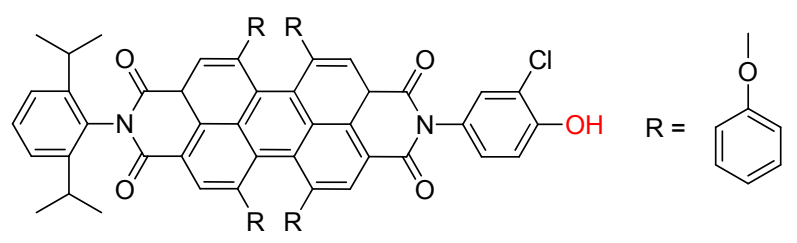

29b

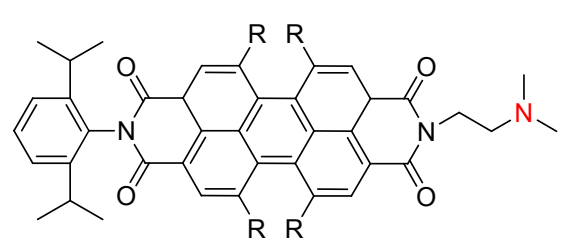

29c
成选择性好, 敏感度高的 $\mathrm{pH}$ 探针, 并且比氨基取代的 同类探针具有更高的柔韧性. 两类取代基团合成的探针 都是基于 PET 原理，但是酚氧基取代的 PDIs 化合物不 需要像氨基取代的化合物一样引入正电荷.

基于这一原理, 石志强课题组 ${ }^{[46]}$ 合成了一种湾位 带差基的化合物 30. 通过改变 $\mathrm{pH}$ 值可以改变羟基的电 离状态，碱性条件下羟基会变成氧负离子，因此造成化 合物的苂光猝灭和紫外吸收的较大红移. 并且该探针能 够用于 K549 细胞内苂光成像.<smiles></smiles>

30

2019 年, 付颖课题组 ${ }^{[47]}$ 将噻吩基团与菲二酰亚胺 端位的乙二胺的氨基结合, 合成了探针 31. 同样是在中 性及碱性条件下，由于端位氨基上的氮原子向芢环发生 PET 作用, 导致芢环荧光猝灭; 酸性条件下氨基变成氮 正离子，阻止了 PET 的发生，因此芢环苂光恢复(Eq. 9). 该探针具有非常好的灵敏性及选择性，并且能够检测至 极酸条件 $(\mathrm{pH}=2.6)$. Bojinov 课题组 ${ }^{[48]}$ 同样基于 PET 原 
理设计了探针 32, 该探针在 PDIs 端位分别引入一个 $N$ 甲基哌嗪. 检测原理与上面的几个探针一致(Eq. 10). 探 针 32 细胞毒性低, 能够用于生物样品中 $\mathrm{pH}$ 值的检测.

2014 年, Dmitriev 课题组 ${ }^{[49}$ 报道了酰亚胺一端含有 低聚胍识别基团的 $\mathrm{pH}$ 荧光探针 33 和酰亚胺位含有阳离 子、湾位带有磺酰基极性基团的水凝胶纳米 $\mathrm{pH}$ 探针 34 . 探针 33 细胞膜穿透性良好, 苂光强度大, 缺点是容易受 微环境影响, 苂光稳定性差. 而探针 34 苂光稳定性好, 在 4.4 8.0 的 $\mathrm{pH}$ 范围内因发生了 PET 效应, 荧光寿命 从 $4.7 \mathrm{~ns}$ 减小为 $3.7 \mathrm{~ns}$, 并被成功用于细胞内 $\mathrm{pH}$ 荧光成
像检测.

牛利课题组 ${ }^{[50]}$ 报道了菲二酰亚胺位置两端连有对 称氨基识别基团并以咪唑为连接基团的水溶性 $\mathrm{pH}$ 荧光 探针 35, 因探针在中性及碱性环境中聚集而荧光淬灭, 能够用于检测 $4.05 \sim 7.05$ 范围的 $\mathrm{pH}$ 值变化, 并被成功 用于葡萄糖识别及定量检测. Garzón-Ruiz 等 ${ }^{[51]}$ 同样基 于不同 $\mathrm{pH}$ 值时化合物的聚集状态不同从而影响光物理 和光化学性质这一原理设计合成了探针 36.

尹梅贞等 ${ }^{[2]}$ 报道了两个基于芢二酰亚胺的树形 $\mathrm{pH}$ 苂光探针分子 37 和 38 . 作者在 PDIs 的湾位置引入五苯

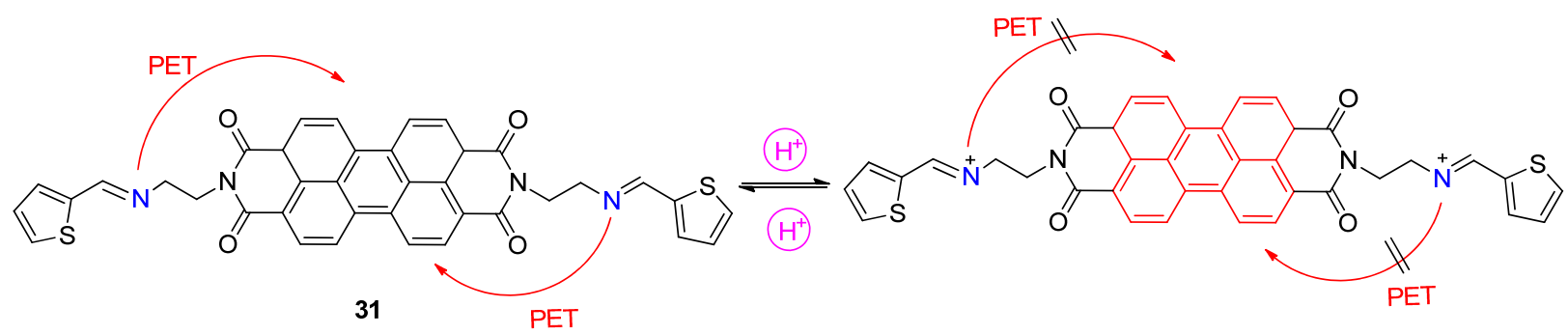

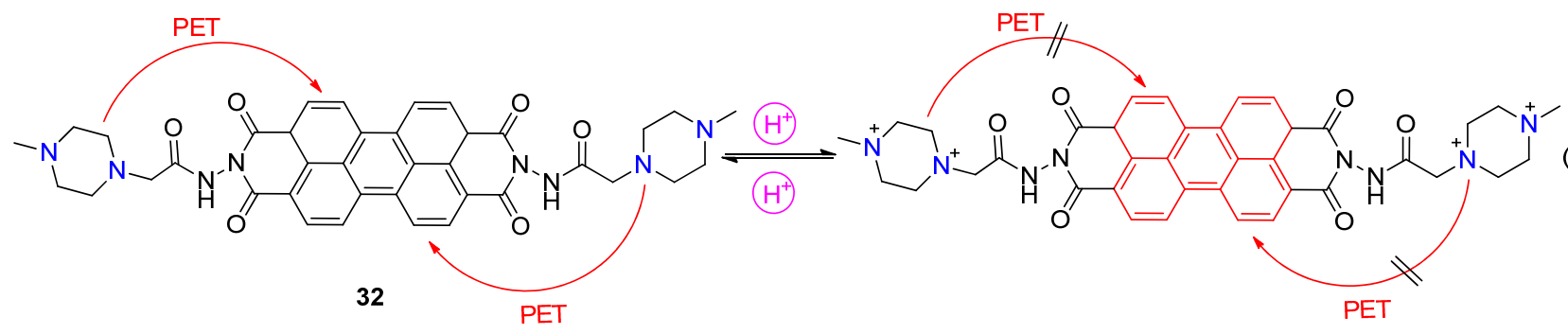

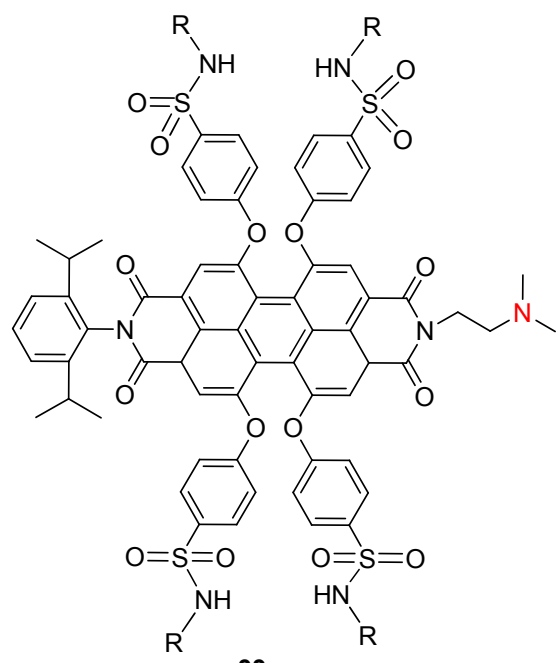

33

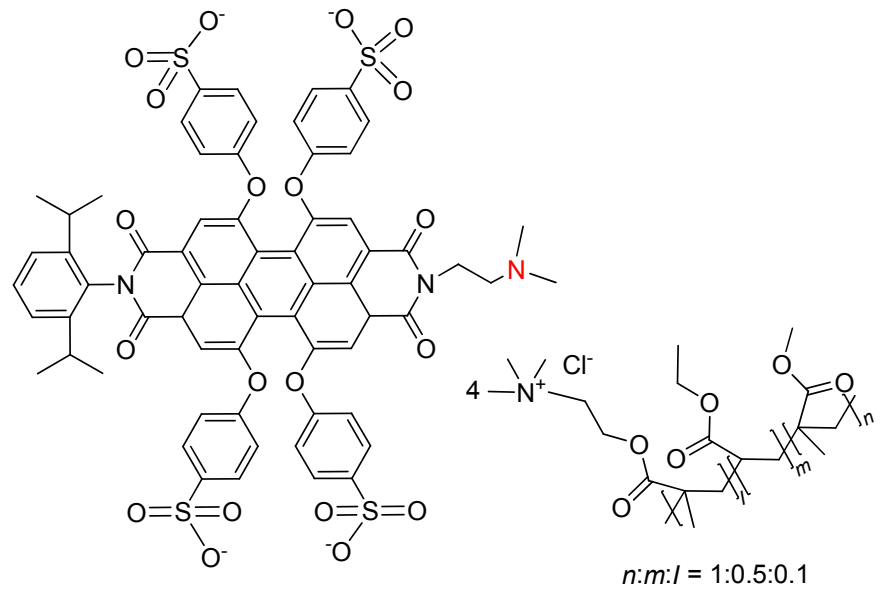

34

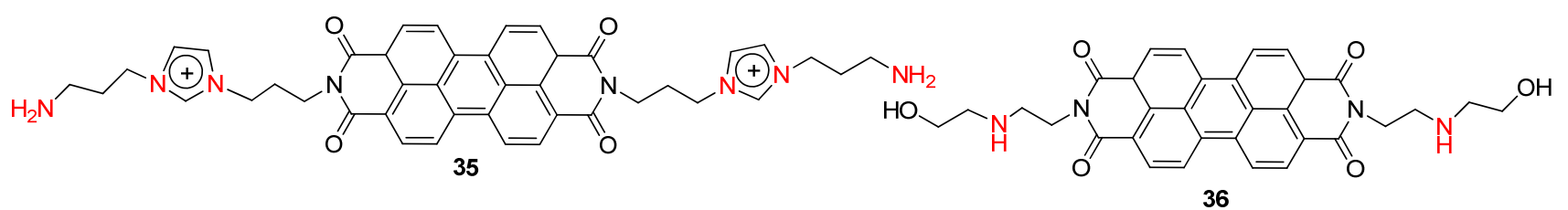


基联苯，联苯末端用氨基或羧基修饰，这样大大增加了 分子的水溶性. 在不同的 $\mathrm{pH}$ 作用下, 其聚集胶束具有 体积相变作用, 同时伴随不同的荧光信号响应.
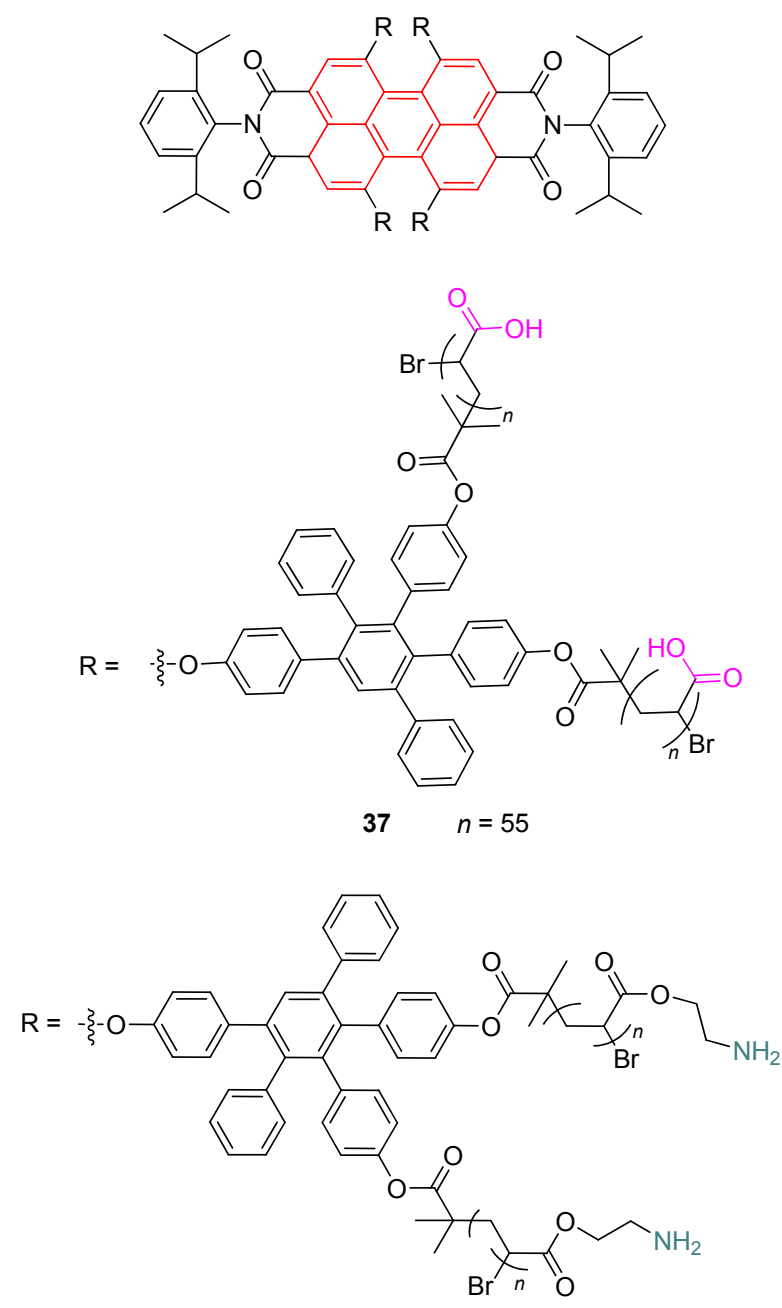

38

在探针设计机制方面, 用于 $\mathrm{pH}$ 的 PDIs 探针主要使 用的是 PET 机理和聚集一解聚机理，与金属离子探针相 比，识别机制更加简单. 因此，在设计检测该类苂光探 针时, 可以考虑引入 $\mathrm{OH}, \mathrm{COOH}, \mathrm{NH}_{2}, \mathrm{NH}$ 等识别位点. 这些识别基团的引入除了提供孤对电子及静电引力外, 同时还能提高 PDIs 类苂光探针的水溶性.

\section{3 阴离子的检测}

$\mathrm{F}^{-}$是最小的阴离子且电负性强, 具有独特的化学性 质, 对生命体有非常重要的作用, 是人体必需的微量元 素之一, 体内含量多少与健康之间存在密切联系 ${ }^{[53]}$. 研 究表明, $\mathrm{F}^{-}$的量对于人体系统而言的 “不过” 与 “过” 之间相差很小, 严格控制氟的摄入量对人体健康非常重 要. 某些含氟物质可用来治疗骨质疏松症和蹯齿, 但摄 入氟过量又会引起骨质或者牙齿 “氟中毒” 。因此, 如 何快速灵敏地检测 $\mathrm{F}^{-}$, 对于生命科学、环境保护乃至国
防应用都是一个极其重要的研究课题 ${ }^{[54]}$.

2012 年，王利民研究组 ${ }^{[55]}$ 设计合成了一种基于 PDI 的新型苂光探针 39. 向探针的二氯甲烷溶液中加入 $F^{-}$ 后, 由于 $\mathrm{F}^{-}$与湾位的氨基形成氢键从而发生 IPT 过程, 最大吸收峰蓝移 $151 \mathrm{~nm}$, 且荧光随之猝灭并伴随着肉 眼可见的溶液颜色变化 (从红色变为黑绿色), 该探针对 $\mathrm{F}^{-}$表现出很好的选择性和很高的灵敏度, 其它的卤族元 素离子对 $\mathrm{F}^{-}$检测不产生干扰(Eq. 11). 基于同样机理该 课题组 $^{[20]}$ 又利用探针 9 , 该探针除能在水溶液中检测 $\mathrm{Cu}^{2+}$ 外还能检测 $\mathrm{F}^{-}$, 在四氢呋喃溶液中加入 $\mathrm{F}^{-}$后溶液 颜色由玫红色变为亮绿色，且其它常见阴离子无干扰. 与此类似，孙小卫研究组 ${ }^{[56]}$ 合成了一种湾位置同时含 有硼氮环的 PDI 衍生物 40, 在三氯甲烷溶液中加入 $\mathrm{F}^{-}$ 后, 由于 $\mathrm{F}^{-}$对湾位置的氮上的氢的强吸电子作用, 导致 该化合物吸收光谱红移，荧光猝灭. 该探针对 $\mathrm{F}^{-}$表现出 极高的灵敏度(响应时间在 $1 \mathrm{~s}$ 内，检测限低至 $1.5 \mu \mathrm{mol} \cdot$ $\left.\mathrm{L}^{-1}\right)$ 及很好的选择性. 石志强课题组 ${ }^{[57]}$ 设计合成了 PDI 的湾位在同一侧含有氨基和羟基的化合物 41, 与湾位置 只含有氨基时氟离子与氨基的活泼氢形成氢键不同，该 化合物溶液中加入 $\mathrm{F}^{-}$时, 湾位的氨基不再参与成键，而 发生羟基上的氢向 $\mathrm{F}^{-}$的分子间质子转移(Intramolecular

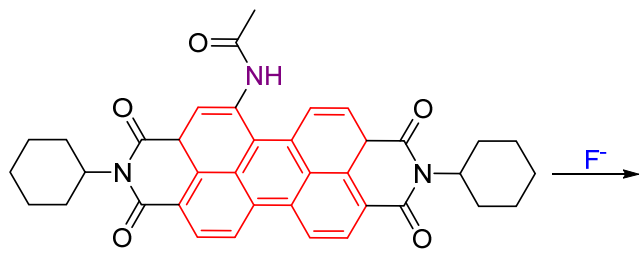

39
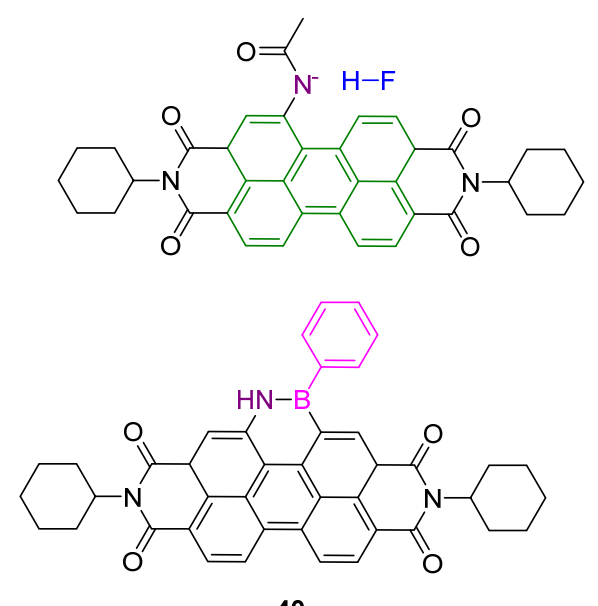

40

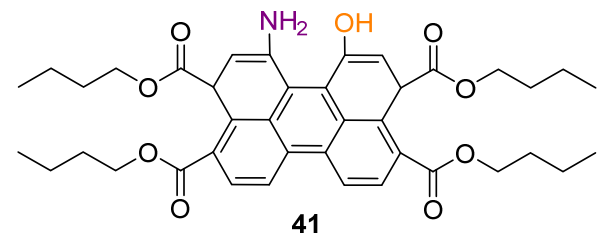


Proton Transfer, IPT)作用. 这就使得化合物吸收光谱发生 明显的红移，荧光基本猝灭，同时溶液颜色由黄色变为 蓝色.

Banerjee 研究组 ${ }^{[58]}$ 合成了酰亚胺位带有丁酸基团的 水溶性 PDI 衍生物 $\mathrm{F}^{-}$苂光探针 42. 电子顺磁共振 (EPR) 分析表明加入 $\mathrm{F}^{-}$后, 由于 $\left(\mathrm{H}_{2} \mathrm{O}\right)_{4} \mathrm{~F}^{-}$与 PDIs 环的 作用导致 PDIs 生成了自由基(Eq. 12); 密度泛函(DFT) 计算证实 $\mathrm{F}^{-}$与探针分子之间有静电作用. 并且, 该探针 与 $\mathrm{F}^{-}$作用后的产物经 $\mathrm{NOBF}_{4}$ 进一步氧化能够再生, 恢 复成原来的分子结构, 说明其对 $\mathrm{F}^{-}$的检测具有可逆性.

当强路易斯碱 $\mathrm{OH}^{-}$和 $\mathrm{F}^{-}$与缺电子的 $\pi$-体系 PDIs 相 互作用时，能够作为亲核试剂进攻 PDIs 形成共价键，使 体系具有顺磁性，导致其光谱发生变化. Saha 课题组 ${ }^{[59]}$ 利用该原理设计了探针 43. 该探针在非质子溶液中与 $\mathrm{OH}^{-}$和 $\mathrm{F}^{-}$发生作用后, 光谱发生明显的变化并伴随溶 液颜色的改变(橙色变为绿色)(Eq. 13). 作者用电化学和 核磁研究了其作用机理.

上述探针对 $\mathrm{F}^{-}$响应主要是通过探针与 $\mathrm{F}^{-}$形成氢键 或路易斯酸碱配位导致其荧光改变, 这类去质子化型 $F$ 探针分子一般含有能够提供质子的基团, 比如 $\mathrm{OH}, \mathrm{NH}$
或 $\mathrm{NH}_{2}$ 等，质子与 $\mathrm{F}^{-}$形成氢键，从而发生 IPT 过程，进 而实现对 $\mathrm{F}^{-}$的检测 ${ }^{[56,57]}$. 除此之外还有其他类型的响 应方式，比如聚集一解聚机理.

白如科课题组 ${ }^{[60]}$ 在菲酰亚胺的酰亚胺位两端分别 接上亲水性的聚乙二醇链和疏水性的笼型的多面体齐 聚倍半硅氧烷 (Polyhedral oligomeric silsesquioxane, POSS), 制备了一种两亲性探针 44, 该化合物可在水溶 液中自组装成纳米粒. 当溶液中存在 $\mathrm{F}^{-}$时, $\mathrm{F}^{-}$会通过催 化反应促使 POSS 的笼状结构水解, 进而引起菲核间 $\pi-\pi$ 作用增强导致分子聚集，达到苂光猝灭的效果，通 过探究苂光发射峰的变化, 可以快速准确实现对 $\mathrm{F}^{-}$的 识别. 任相鬼课题组 ${ }^{[61]}$ 在 PDIs 的两端均引入了 POSS 基团, 并在湾位置引入乙酰胺设计合成了探针 45 , 与探 针 44 相比，探针 45 对于 $\mathrm{F}^{-}$具有更高的灵敏度和选择性， 且检测限低至 $1.64 \times 10^{-8} \mathrm{~mol} \cdot \mathrm{L}^{-1}$. 同样基于聚集状态 影响化合物的苂光性质这一机理, Thilagar 课题组 ${ }^{[62]}$ 设 计并合成了探针 46. 三芳基硼烷(TAB)的加入提高了菲 系衍生物在有机溶剂中的溶解度, 该化合物可以快速准 确地识别 $\mathrm{F}^{-}$.

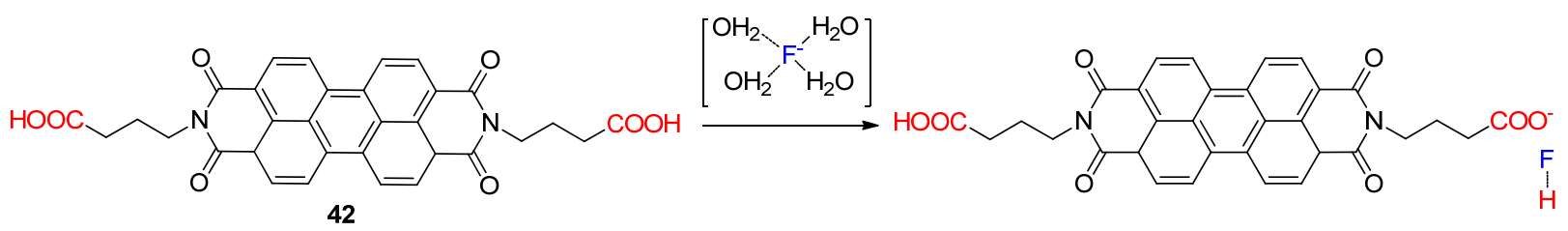<smiles></smiles><smiles>O=P</smiles>

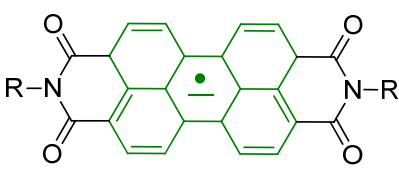

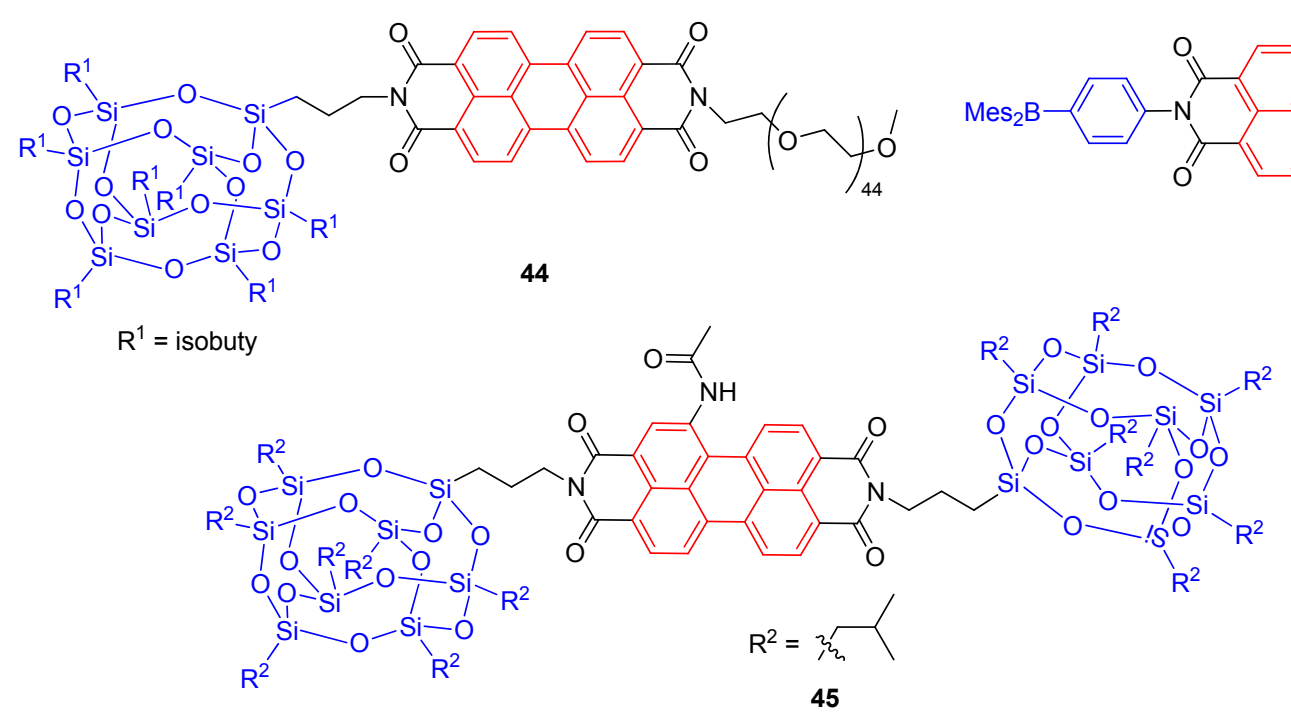


除此之外，任君等设计合成了一种含有四个硅氧键 的 PDsI 苂光探针 $47^{[63]}$. 利用 $\mathrm{F}^{-}$诱导硅氧键断裂, 使 ICT 过程受到抑制，导致探针分子的苂光猝灭. 实现了 对 $\mathrm{F}^{-}$的高选择性、高灵敏度识别, 响应速度快 $(1 \mathrm{~min}$ 内 完成), 检测限低至 $3.5 \times 10^{-8} \mathrm{~mol} \cdot \mathrm{L}^{-1}$.

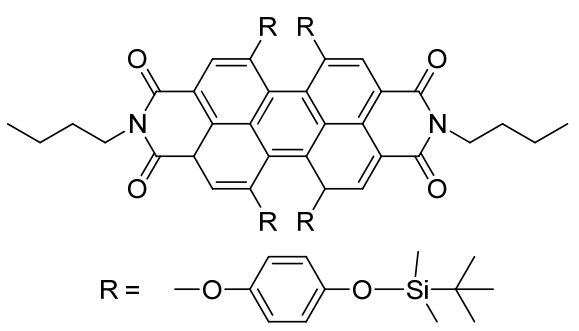

47

在非生物体系中检测 $\mathrm{F}^{-}$, 检测环境对探针的溶解 性没有过于苛刻的要求, 但要求较高的检测灵敏度, 而 PDIs 探针恰好具有水溶液中溶解性较差、灵敏度高这一 特点, 因此对拓宽以 PDIs 为发色团的探针的应用范围 有很大的优势.

\section{2 气体类探针}

相比固体和液体类的污染物, 气体污染物对人体的 危害更加猝不及防. 气体类探针也是研究人员广泛关注 的一类探针. 固体苂光检测作为一种简单、快捷的检测 技术, 近年来在化学、材料和环境科学领域得到了广泛 的关注. 基于有机材料的固态苂光传感器通常要求两个 先决条件: 一个是使用的有机物质在固态中表现出较强 的苂光(常见的有机菼光材料一般是在溶液中使用, 这 是因为固态时常发生苂光自淬灭), 另一个是合适的绑 定或吸收可以捕获分析物分子的位点.

\section{1 用于含氮类气体检测的探针}

刘育课题组 ${ }^{[64]}$ 合成了一种能够检测胺类蒸气的探 针 48. 该探针在酰亚胺位修饰 $\beta$-环糊精, 能够组装形成 棒状纳米结构并具有很好的偏光性(Scheme 5). 将聚偏 二氟乙烯薄膜浸入这类 PDIs 溶液中, 得到一个染料薄 膜, 这种薄膜能够在有机胺类气体或某些挥发性有机化 合物的存在下苂光发生淬灭, 但对苯胺气体有很好的选 择性. $33 \mathrm{mg} / \mathrm{L}$ 的苯胺气体能够使组装体荧光发生 $30 \%$ 的猝灭, 而 $4100 \mathrm{mg} / \mathrm{L}$ 的甲苯气体才能使其发生 $15 \%$ 的 猝灭.

房喻等 ${ }^{[65]}$ 在 PDIs 端位引入胆固醇, 设计并合成了 对有机胺超灵敏的荧光薄膜探针 49. 胆固醇的引入提 高了菲二酰亚胺的成膜能力及成膜后的薄膜稳定性, 同 时强化了该薄膜对有机胺的富集能力, 从而使其对有机 胺的检测达到了 $\mathrm{ng} / \mathrm{L}$ 级别. 由于采用的是非侵入

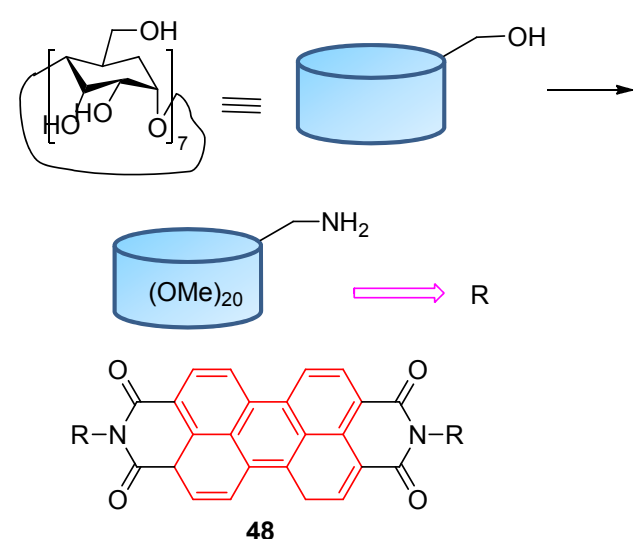

图式 5 探针分子 48 的分子结构

Scheme 5 Molecular structure of probe $\mathbf{4 8}$
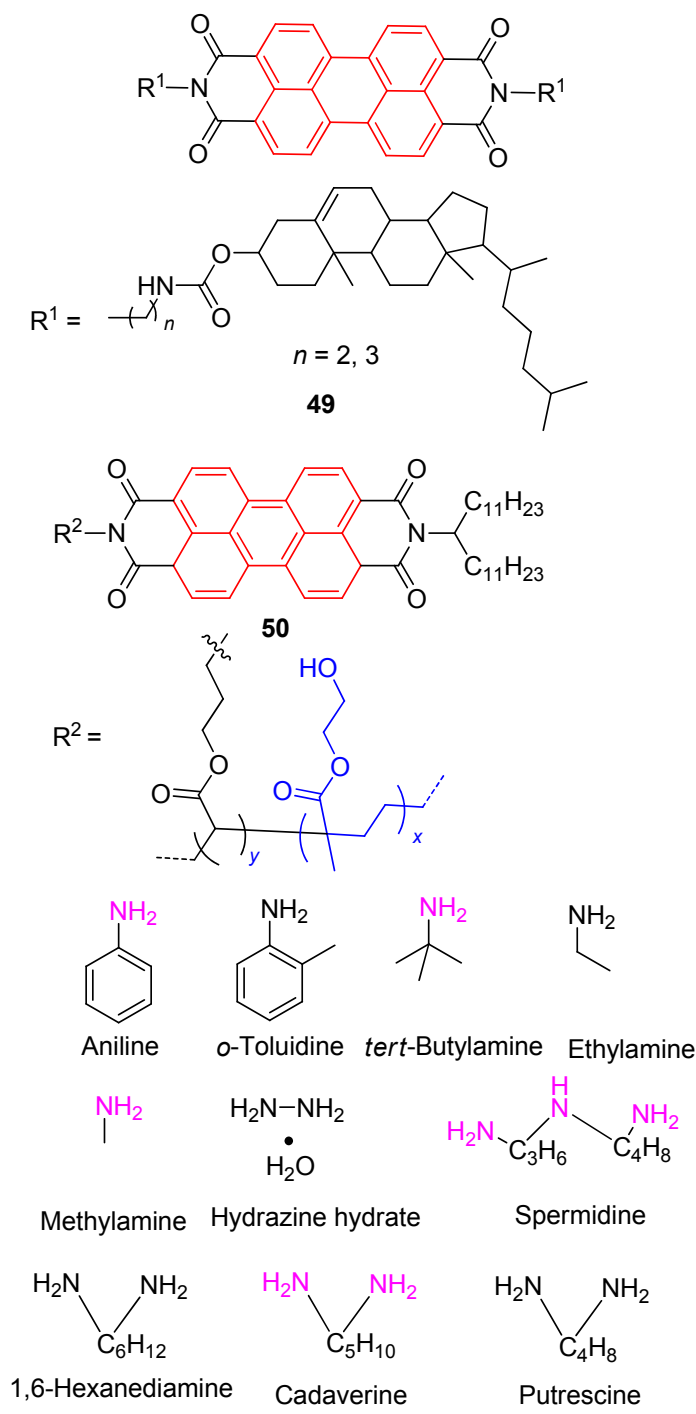

性接触且响应具有可逆性，该探针分子可以对环境中有 机胺浓度进行实时监控. 该课题组 ${ }^{[66]}$ 在该工作的基础 上又设计并合成了一个以苂光共聚物(HEMA-co-PBI)为 基体, 以菲为胺敏感单元的气敏薄膜探针 50. 实验结果 
表明, 菲环是传感器的关键决定因素, 它决定了探针系 统的特殊传感性能, 特别是对不同目标分子的识别响应 时间; 而惰性单体 HEMA 共聚物的存在降低了 PDIs 之 间相互作用，并通过羟基与胺基之间的氢键促进了不同 类型的胺蒸汽的吸附.

魏志祥等 ${ }^{[67]}$ 研究发现糖类基团取代的荘酰亚胺类 化合物探针 51 在不同比例的混合溶剂 $\left(\mathrm{H}_{2} \mathrm{O} / \mathrm{DMF}\right)$ 中可
以分别聚集成带状和纤维状结构，其中纳米带状结构比 纤维结构展现出更好的联氨气敏响应(图 2). 最近该课 题组 ${ }^{[68]}$ 在 PDIs 的湾位分别引入 $\mathrm{S}$ 和 $\mathrm{Se}$, 得到了探针 $\mathbf{5 2}$, 该探针利用分子间的范德华力进一步调控分子聚集体 的形貌，进而影响对 $\mathrm{NH}_{3}$ 的气敏响应(图 3).

问东航课题组 ${ }^{[69]}$ 报道了荘酰亚胺(PTCDI-Ph) 和六 苯基(p-6P)组成的高度有序的异质结薄膜气体探针 53 ,

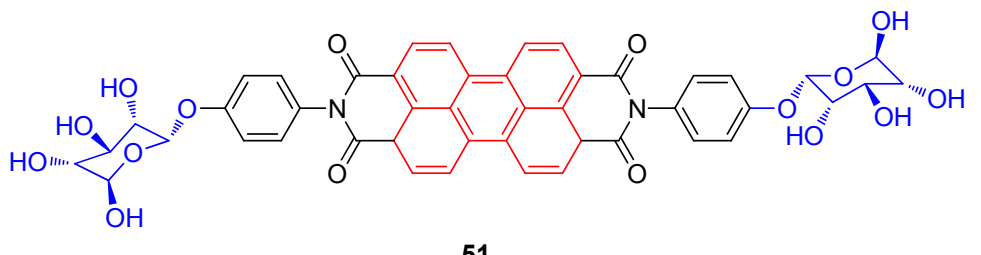

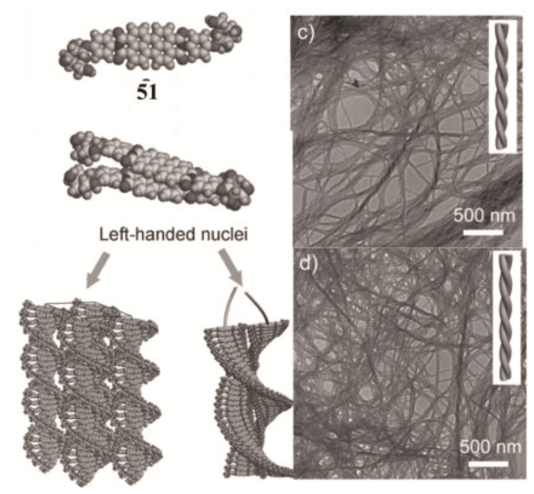

图 2 探针 51 的分子结构和自组装的过程

Figure 2 Molecular structure and self-assembly processes of probe $\mathbf{5 1}$

(a)<smiles></smiles>

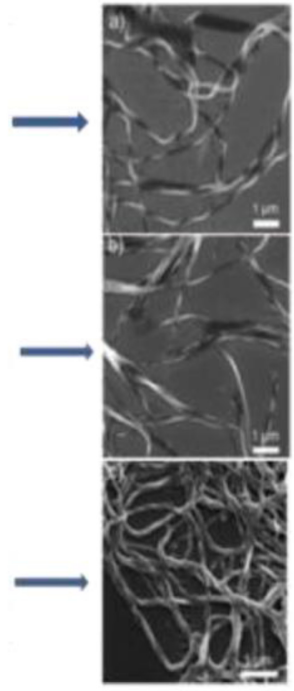

$52 c$

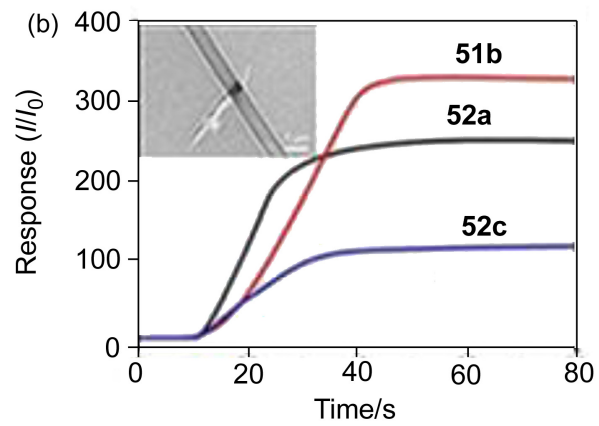

(c)

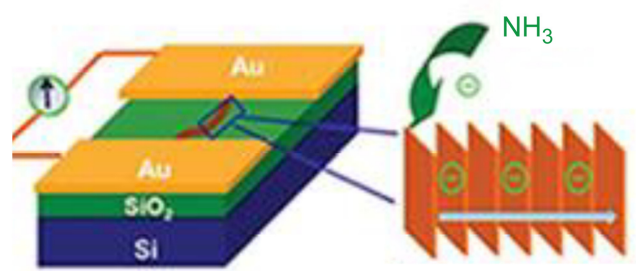

Perylene anionic radica

图 3 探针 52 的分子结构(a)、探针 52 在氨中的自组装过程及响应(b)和传感机理(c)

Figure 3 Molecular structure (a), self-assembly processes and response $\left(I / I_{0}\right)$ of probe $\mathbf{5 2}$ devices in ammonia (100 $\left.\mathrm{mg} / \mathrm{L}\right)(\mathrm{b})$ and schematics of the sensing mechanism (c) 
探针 53 在室温下对 $\mathrm{NO}_{2}$ 具有较快的响应/恢复特性以及 良好的稳定性, 此外, 当酞菁与上述单异质结形成双异 质结时对 $\mathrm{NO}_{2}$ 的灵敏度明显比单异质结提高很多. Iyer 课题组 ${ }^{[70]}$ 研究表明组氨酸取代的萠酰亚胺(PDI-HIS)薄 膜气体探针 54 在室温下通过电流强度的变化检测 $\mathrm{NH}_{3}$ 气体. 组氨酸作为取代基团改变了菲酰亚胺的固态聚集 形貌及氧化还原电位, 使得此器件的传感性能得到了较 大的提升，最低检测限达到 $0.56 \mathrm{mg} / \mathrm{L}$.
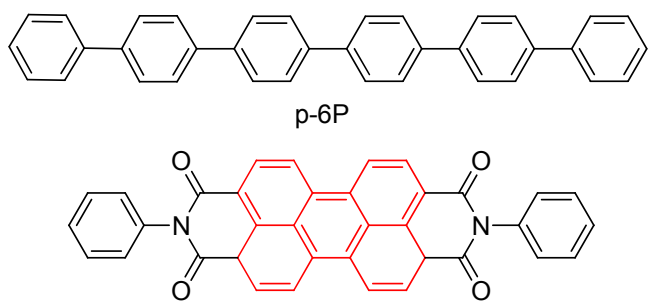

53

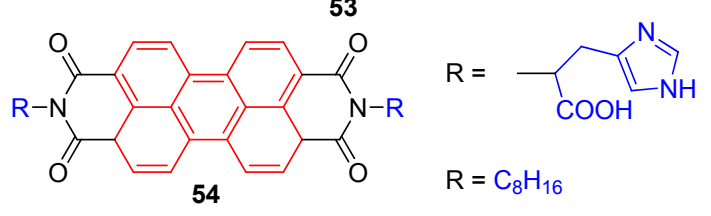

刘中华等 ${ }^{[71]}$ 利用手性樟脑磺酸取代的菲酰亚胺衍 生物自组装的方法制备了两个乙二胺传感器 55 和 56. 探针 55 和 56 对乙二胺气体都表现出了优越的灵敏度、 响应恢复时间及选择性, 且探测极限分别低至 1.07 和 $0.86 \mathrm{mg} / \mathrm{L}$. X 射线衍射 (XRD)结果表明分子间的 $\pi-\pi$ 相 互作用以及有效的 $\pi-\pi$ 重叠在电流增加及器件稳定性中 起着重要的作用.

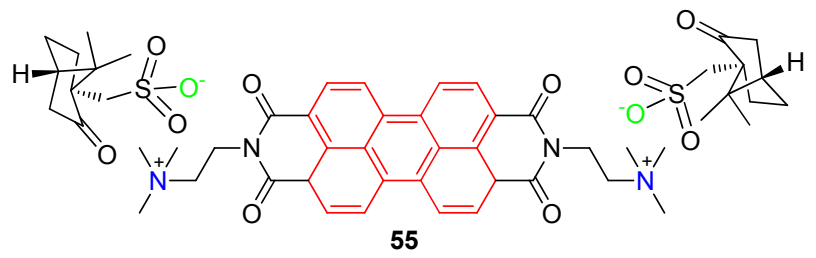

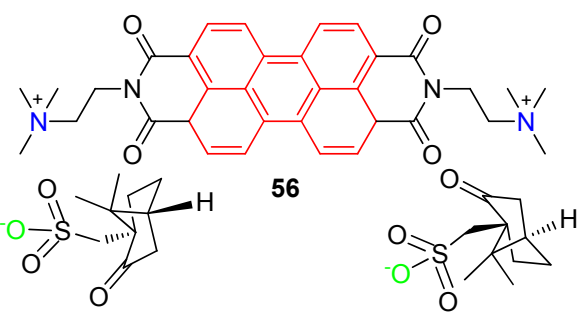

张海泉课题组 ${ }^{[72]}$ 设计合成了探针 57. 探针 57 组装 成的扭曲的菲酰亚胺衍生物薄膜对联氨气体具有较高 的选择性、重现性以及超快的响应, 并且响应与浓度之 间具有一定的线性关系. 刘辉彪课题组 ${ }^{[73]}$ 报道了无机/ 有机 $(\mathrm{ZnS} / \mathrm{PTCDA})$ 核/壳纳米颗粒薄膜探针 58 . 探针 58 对苯胺气体具有快速、高灵敏度和选择性的敏感响应, 并且检测限低至 $100 \mu \mathrm{g} / \mathrm{L}$ (Eq. 14).
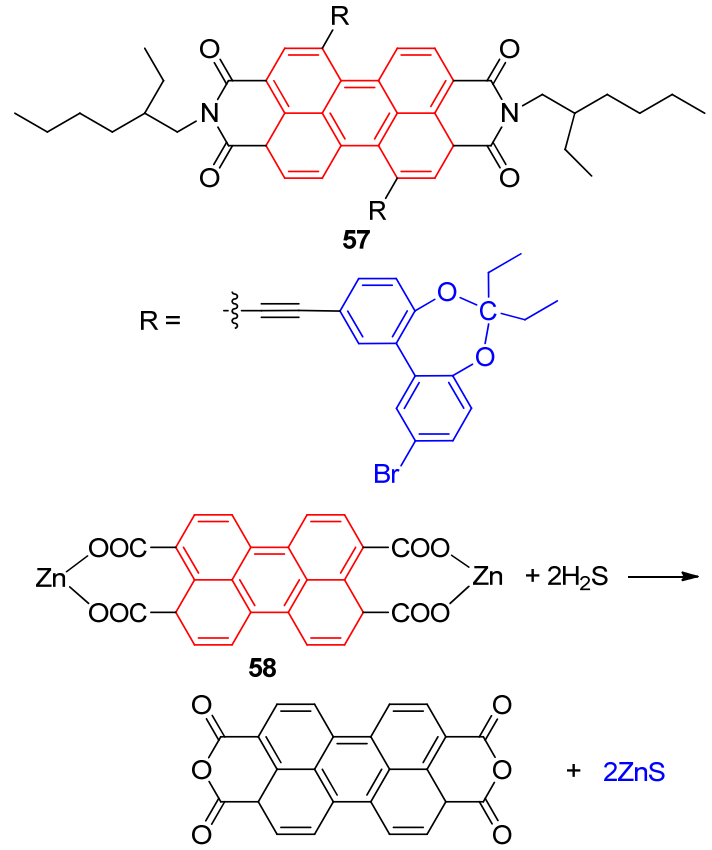

(14)

2017 年黄永伟等 ${ }^{[74]}$ 利用胺位环己胺基取代且湾位 分别是四苯氧基、对叔丁基苯氧基、对四甲基丁基苯氧 基取代的萠酰亚胺衍生物作为传感材料成功地制备了 水合肼传感器 59(图 4). 该研究表明 PDIs 湾位的芳香族 取代基、长度及分支的烷基链的不同都会改变晶体结

A
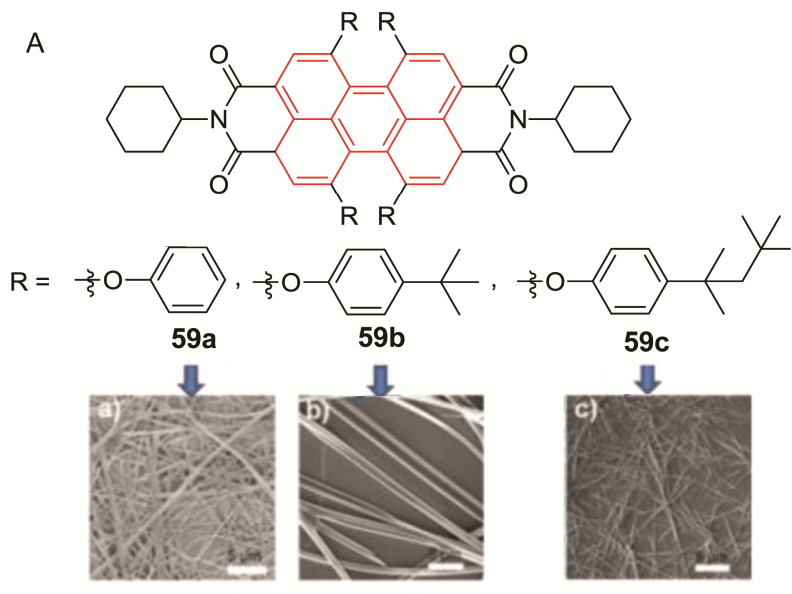

B

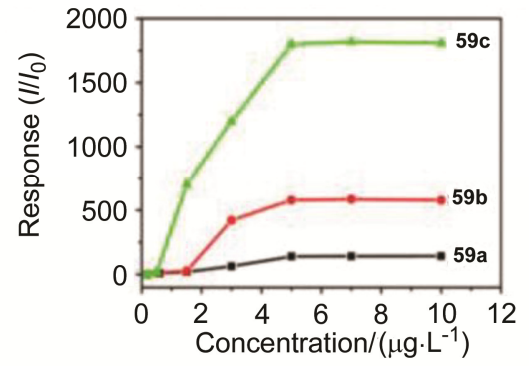

图 4 探针 59 的分子结构和形成聚集体后的形貌(A)以及对肼 蒸汽的响应调制一浓度曲线(B)

Figure 4 Chemical structure of probe 59, SEM images (A) and the response modulation-concentration curves of $\mathbf{5 9}$ devices in hydrazine vapor (B) 
构、 $\pi-\pi$ 堆积及能级结构进而都会对传感性能产生影响. 最近，朱沛华课题组 ${ }^{[75]}$ 设计并合成了一种新颖的 有机-无机杂化微米带 60 . 与未杂化的分子的微米棒相 比，对于三甲胺的气敏响应有明显的提高.

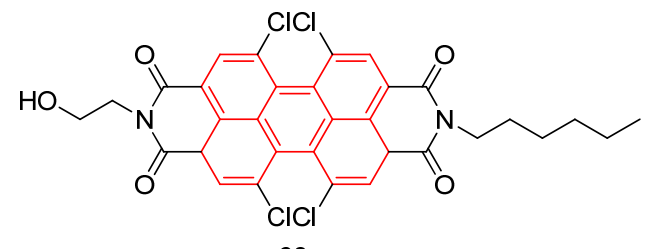

60

\section{2 用于其他气体检测的探针}

Acikbas 等课题组 ${ }^{[76]}$ 利用探针 53 制备了一种新颖的 菲酰亚胺薄膜传感器, 用该薄膜制备而成的气敏元件在 室温下对氯仿、苯、甲苯以及乙醇等一系列挥发性有机 物(VOC)都表现出一定的灵敏度, 尤其是对氯仿具有更 快的响应以及更低的检测限，这更加有利于实际应用.

房喻课题组 ${ }^{[77]}$ 用氯缁醇功能化杯 [4]吡咯和 PDIs 基 才制备了超分子复合物 61 , 经氨处理后形成脱质子的
二酸. 该复合物能有效检测乙醇中的 2,4,6-三硝基甲苯 (2,4,6-Trinitrotoluene; TNT), 检测限是 $80 \mathrm{nmol} \cdot \mathrm{L}^{-1}$. 检 测机理是 TNT-杯[4]-吡咯的缔合破坏了超分子复合的结 构，诱导荧光猝灭. 该探针分子对 2,4-二硝基甲苯有一 定的选择性，表现为有一定的荧光猝灭. 另外，用苯酚 蒸汽猝灭探针分子 61 膜的苂光，检测限为 $1 \mu \mathrm{g} / \mathrm{L}$. 更多 的取代酚也被证明可以抑制该系统的苂光，但是效率较 低(Scheme 6).

\section{3 生物分子类探针}

在基因-蛋白质-功能-疾病之间的复杂关系中，生 物活性小分子已成为其间联系的枢纽, 在组织和器官的 结构和功能的稳态维持中发挥重要作用. 生物小分子含 量和表达水平的异常可以引起多种疾病, 直接影响生命 活动的正常进行. 例如, ATP 作为生物体的能量来源, 参与绝大多数的生命活动, 如 DNA 的合成与转录、信 号传递和细胞新陈代谢等. 细胞 ATP 的浓度异常有可能 导致低血糖、贫血症和心脑血管疾病等，因此 ATP 的含 量测定可以作为多种疾病的诊断依据. 谷胱甘肽是细胞

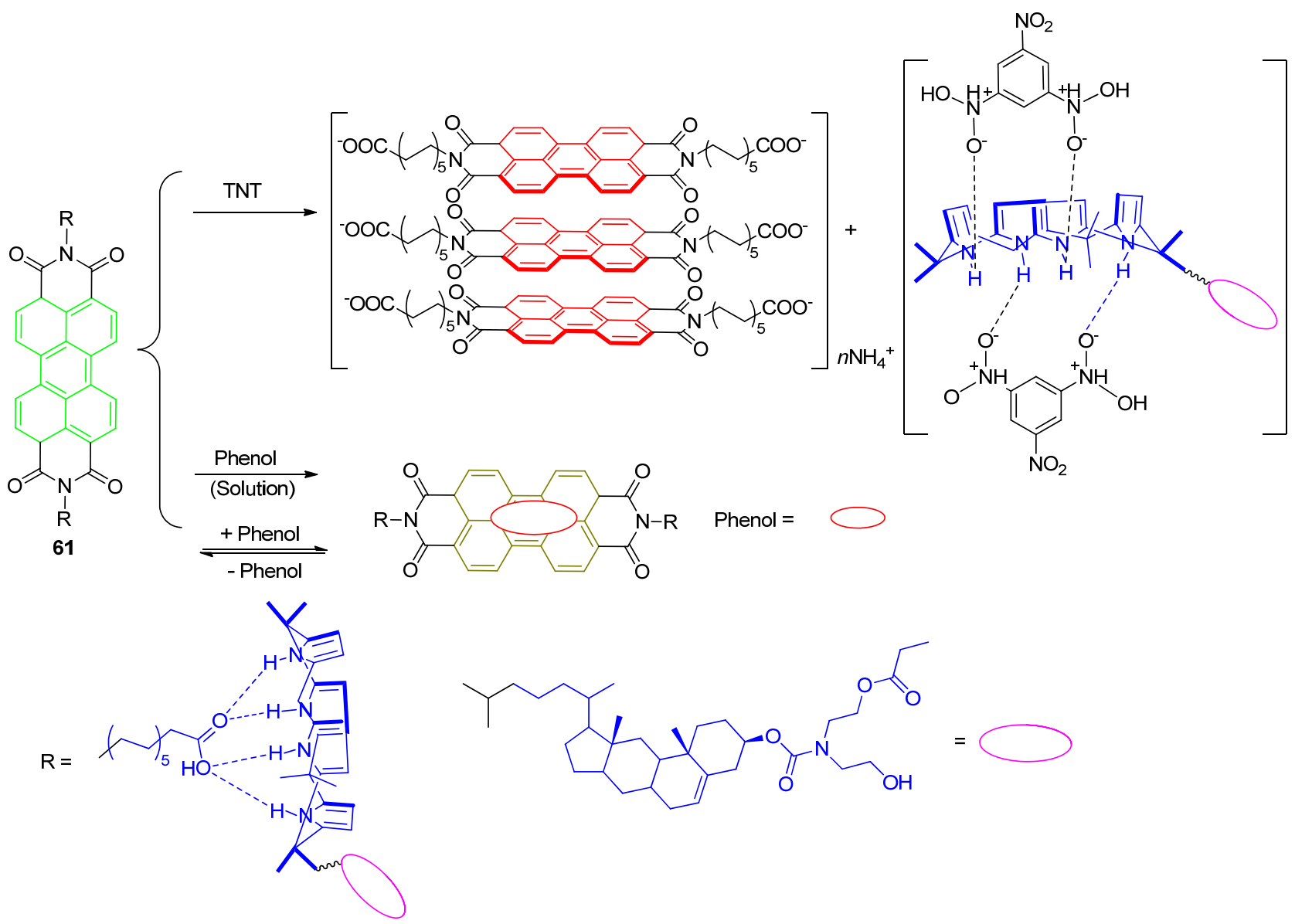

图式 6 探针 61 的分子结构和苂光超分子聚集体的形成和解聚以及其与 TNT 和苯酚在两种不同模式下的相互作用 Scheme 6 Molecular structures and schematic representation of the formation and disassembly of the probe $\mathbf{6 1}$ and its interaction with TNT and phenol in two different modes 
内含量最多的生物硫醇, 是一类具有还原能力的活性物 质. 谷胱甘肽可以帮助清除体内过量的自由基, 调节机 体氧化还原平衡, 在抗衰老、抗肿瘤、提高机体自愈能 力和预防神经退行性疾病等方面具有十分重要的意义. 葡萄糖是自然界分布最广的单糖，也是人体中最重要的 单糖，在生命体的新陈代谢等过程中扮演重要角色. 葡 萄糖在人体内的含量异常也会引起各类疾病, 例如, 含 量过高会引起肥胖症或糖尿病, 含量过低会引起低血糖 或昏厥等, 因此，血液中的葡萄糖的含量可以用来评估 身体的健康状况. 而 PDI 类探针的易于合成、可修饰位 置多、光热及化学稳定性等优点, 使其能够在生物探针 领域发挥出独特的性能. 用于生物分子检测的 PDI 衍生 物类苂光探针检测机理主要有分子聚集-解聚和氨基质 子化等引起影响荧光发射光谱的变化.

DNA/RNA 结构与功能的研究一直是生物医学和材 料化学等领域的热点. 菲酰亚胺荧光染料不仅可以提供 稳定的荧光信号, 还具有强的堆积作用, 因此小分子的 菲酰亚胺探针常被用于与碱基对作用研究 DNA/RNA 的 结构稳定性、耐高温和标记等方面 ${ }^{[78 ~ 82]}$.

Wagenknecht 等 ${ }^{[83}$ 将带有磷酸基团的 62 与寡核苷 酸偶联，作为碱基插入三种代表性的 DNA 链段的中间 或是两端, 使 DNA 的结构与功能发生变化. 他们发现 碱基对配对错误或者缺失都可以引起菲衍生物荧光发 射光谱的变化, 更有意思的是当碱基对配对正确时, 可 以得到和其它有问题的 DNA 链不一样的苂光发射谱, 从而可以检测到碱基对缺失及突变等, 而且可以定量检 测正常 DNA 的比例(图 5). 因此探针 62 可以作为一种 新型的 DNA/RNA 苂光探针, 研究 DNA/RNA 中碱基对 的缺失和错配.

于聪等 ${ }^{[84]}$ 在 PDIs 端位引入末端带有羧基的长链烷 烃, 合成探针 63. 该探针在 Tris- $\mathrm{HCl}$ 的缓冲溶液中具有 强烈的荧光; 当加入阳离子型聚合物时, 由于羧基与阳 离子作用，导致化合物发生诱导聚集，从而苂光猝灭; 再加入携带阴离子的 DNA 时, 阳离子聚合物更倾向于 与 DNA 络合, 从而释放探针 $\mathbf{6 3}$, 苂光得到恢复(Scheme 7). 该探针对 DNA 的检测极限能够达到 $2 \mathrm{pmol} \cdot \mathrm{L}^{-1}$. 将 DNA、PDI 和阳离子型聚合物作为一个检测系统, 这个 系统可检测碱性磷酸酶(ALP). 该课题组 ${ }^{[85]}$ 设计合成了 在端位置的氮原子上带正电荷的 PDIs 衍生物探针 64. 探针本身在水溶液中表现出化合物本身的单体苂光性 质，与 DNA 结合后探针发生聚集，导致苂光强度减弱， 向该体系中加入蛋白分子后荧光逐渐恢复. 该体系对蛋 白质分子具有良好的选择性和敏感性, 且荧光增加的强 度与加入的蛋白质的量在一定范围内表现为线性相关, 这为定量检测蛋白质的应用方面提供了一种方法.

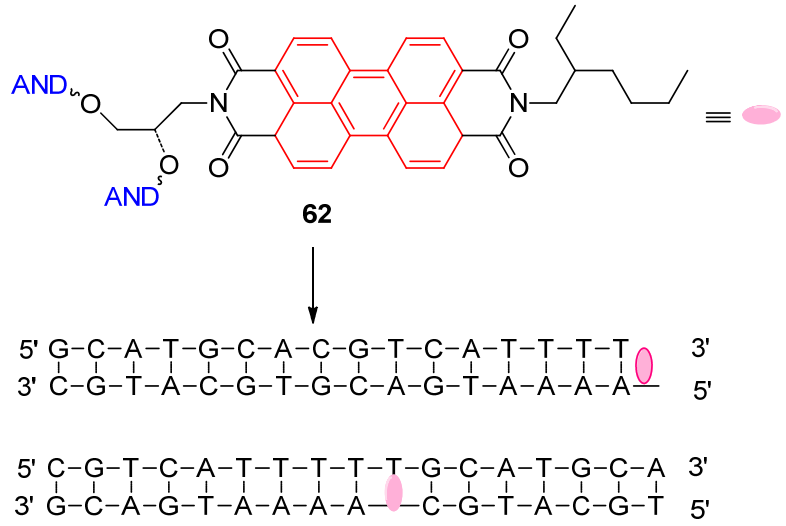

图 5 探针 62 的分子结构和对 DNA/RNA 的识别机理 Figure 5 Molecular structures and detection mechanism of probe $\mathbf{6 2}$

Tam-Chang 等 ${ }^{[43]}$ 设计合成的端位被叔胺基取代的 不对称萠酰亚胺探针 27 在 $\mathrm{pH}$ 变化时因叔胺质子化的变 化能够引起苂光发射光谱的变化，在 $\mathrm{pH} 7.5 \sim 9$ 范围内， 随着 $\mathrm{pH}$ 增大, $585 \mathrm{~nm}$ 处的苂光峰逐渐减小, 而 $695 \mathrm{~nm}$ 处的苂光峰逐渐增强. 在生理 $\mathrm{pH}$ 范围, 该探针还可以 实现对 DNA 的检测并实现苂光信号的比率型变化. 与 以往标记 DNA 的荧光分子检测 DNA 时单一的苂光信 号增强或减弱相比, 这种比率型变化避免了某些可以使 苂光增强的干扰源对检测的影响. 该探针仍然是利用了 聚集-解聚导致的苂光变化原理.

2009 年, Yoon 课题组 ${ }^{[86]}$ 设计合成探针 65 . 探针 65 通过络合锌离子后对三磷酸尿苷(UTP)和二磷酸尿苷 (UDP)具有较高的选择性识别能力, 且不受其他小分子 的干扰(Scheme 8). 间立伟等 ${ }^{[87]}$ 又利用该化合物对三磷 酸腺苷(ATP)进行了检测, 当 ATP 存在时探针荧光增强. 该探针虽然能够在纯水溶液中应用，但是选择性较差.

酶探针是检测生物系统中酶活性及阐明酶功能和 机理的有效的分子工具. 乙酰胆碱酯酶(AChE)是中枢 和外周神经系统中的一种初级胆碱酯酶. 它能催化乙酰 胆碱水解成胆碱和乙酸盐, 有助于维持神经递质乙酰胆 碱的水平. 甲胎蛋白(AFP)是一种糖蛋白，与多种肿瘤 的发生发展密切相关. 于聪课题组 ${ }^{[88]}$ 在金属配位聚合 物的原位基因比的基础上，利用探针 $\mathbf{6 3}$ 检测 AChE 和 AFP. 乙酰硫代胆碱氯在 AChE 存在时会水解成硫代胆 碱, $\mathrm{Ag}^{+}$与生成的硫代胆碱形成带正电荷的金属配位聚 合物，诱导带负电荷的菲探针聚集，从而形成探针的激 基缔合物的发射. 激基缔合物与单体的发射强度与 $\mathrm{AChE}$ 的浓度成线性比例. 因此建立了一种检测 $\mathrm{AChE}$ 和 AFE 的方法, 对 AChE 的检测限为 $0.02 \mathrm{mU} \cdot \mathrm{mL}^{-1}$. 仍 然利用在聚集一解聚状态不同时荧光光谱的变化, 王克 让等 ${ }^{[89]}$ 设计了能够特选择性检测刀豆素 $\mathrm{A}$ 的探针 66 , 

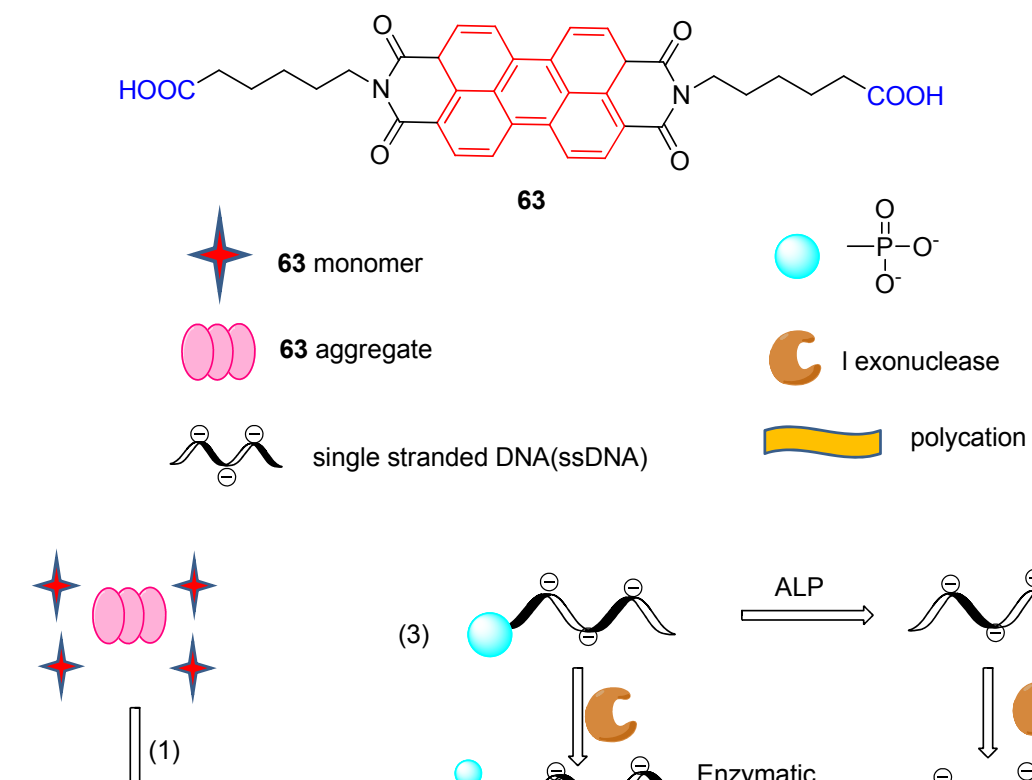

(3)

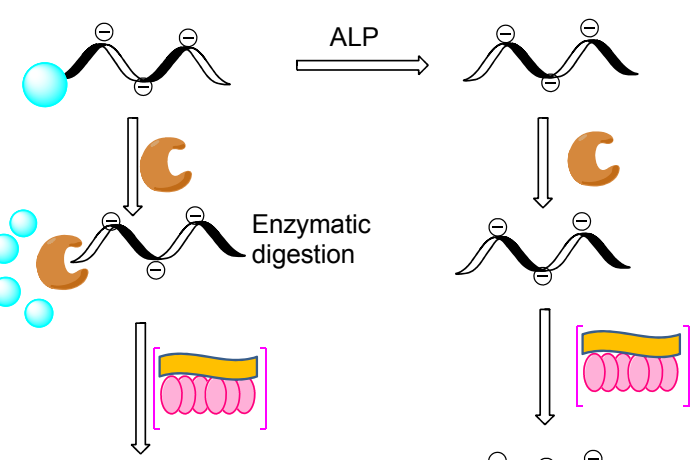

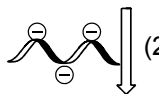

62 aggregation

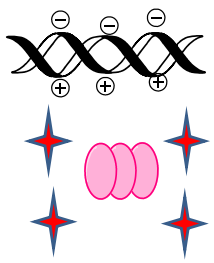

$\mathbf{\ominus}_{\oplus}^{\ominus} \stackrel{\ominus}{\beta}$

$0 \mathrm{Om}$

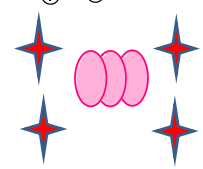<smiles></smiles>

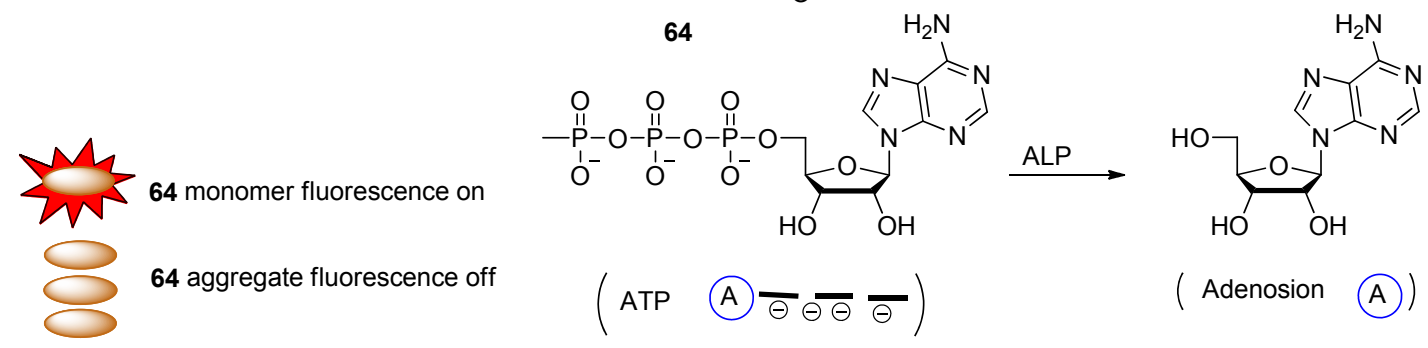

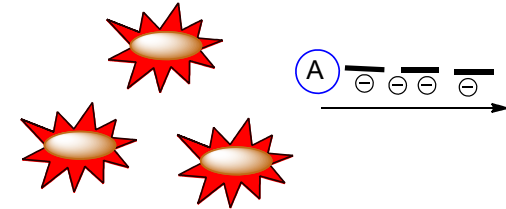

64

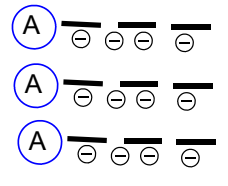

Aggregation

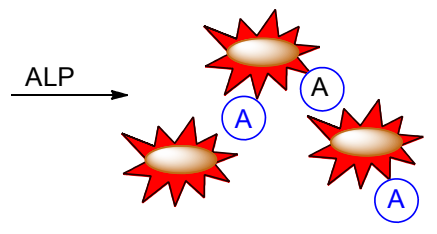

De-aggregation

图式 7 探针 63 和 64 的分子结构和对 ALP 的识别机理

Scheme 7 Structures and detection mechanism to ALP of probes 63 and 64 


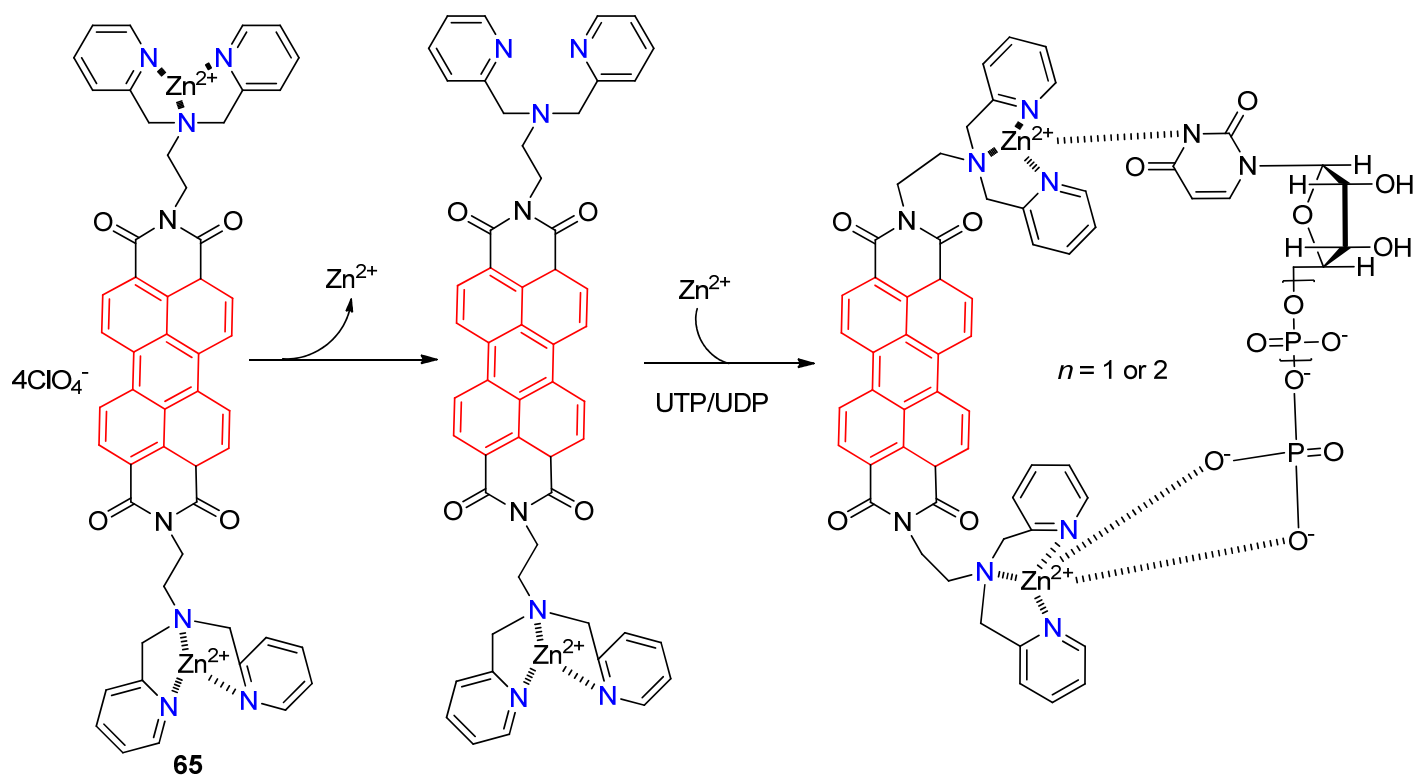

图式 8 探针分子 $\mathbf{6 5}$ 检测 UTP/UDP 的识别机理

Scheme 8 Probe molecule $\mathbf{6 5}$ detects the recognition mechanism of UTP/UDP

该探针在 PDIs 的湾位修饰甘露糖, 甘露糖能够特异性 靶向刀豆素 $\mathrm{A}$, 探针 66 对刀豆素 $\mathrm{A}$ 的结合常数为 $8.2 \times$

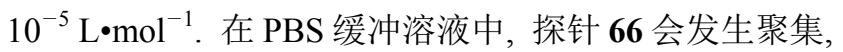
苂光淬灭, 在加入刀豆素 $\mathrm{A}$ 后, 探针发生解聚集, 苂光 恢复. 该探针能够用于小鼠巨噬细胞中刀豆素 $\mathrm{A}$ 的特异 性识别标记.
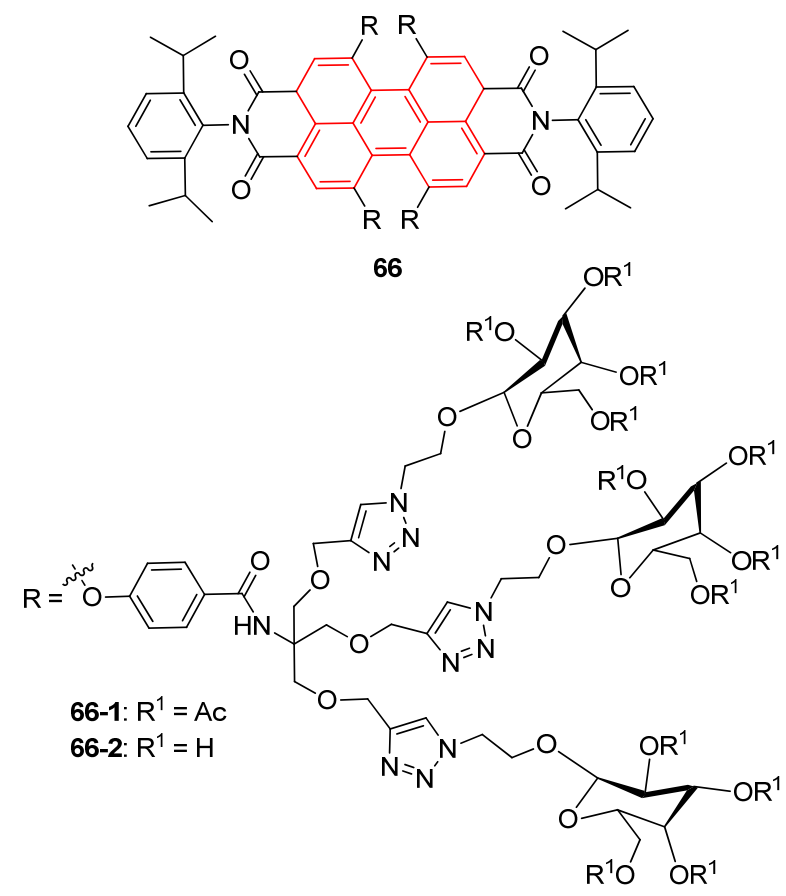

Stevens 课题组 ${ }^{[90]}$ 报道了一种基于菲二酰亚胺类衍 生物的蛋白水解酶探针 67. 该探针是在 PDIs 的酰亚胺 部分修饰上天冬氨酸基团, 天冬氨酸既可以用作亲水基
团增加探针的水溶性，又可以与蛋白水解酶含有的氨基 结合形成聚集体，从而引起吸收和荧光光谱的变化. 由 于该探针的空间体积较小，可以顺利地通过细胞膜，因 此可以直接应用于细胞中蛋白水解酶的检测, 检出限为 $0.51 \mathrm{mmol} \cdot \mathrm{L}^{-1}$. 该探针仍然是利用聚集一解聚状态不同 时光谱的变化而设计的.

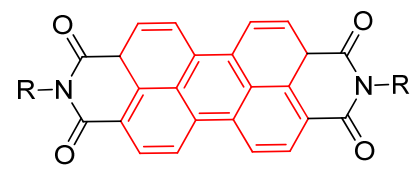<smiles>[R][C@H](CC(=O)O)C(=O)O</smiles>

67

正常情况下, 适量水平的 $\mathrm{H}_{2} \mathrm{O}_{2}$ 对生物体是必需且 有益的, 在多种正常的生理过程中都起着相当重要的作 用 ${ }^{[11,92]}$. 例如, 哺乳动物细胞内产生一定量的 $\mathrm{H}_{2} \mathrm{O}_{2}$ 来调 节多种生理过程, 如细胞的迁移、增殖以及分化 ${ }^{[93]}$. 但 过量产生的 $\mathrm{H}_{2} \mathrm{O}_{2}$ 会导致氧化损伤的积累, 从而引起衰 老和癌症 ${ }^{[94]}$ 、心血管疾病 ${ }^{[95]}$ 、阿尔兹海默病 ${ }^{[96]}$ 等一系列 的疾病. $\mathrm{H}_{2} \mathrm{O}_{2}$ 的高灵敏度、高选择性可视化检测对重大 疾病的致病/治病机理研究具有重要意义. Soh 及 Imato 等 ${ }^{[97,98]}$ 报道了用于检测氢过氧化物的荧光探针 68. 该探 针在 PDIs 的端位引入三苯基膦基团, 在没有与氢过氧 化物反应前，由于三苯基膦中磷原子发生向 PDIs 的 PET 作用, 导致荧光团的荧光淬灭; 与氢过氧化物反应 后，磷原子被氧化，PET 作用被禁止，荧光团的荧光恢 复(Eq. 15). 在氢过氧化物检测的实验中, 随着氢过氧化 物浓度的增大，探针 68 的荧光强度不断增强. 该探针具 有良好的选择性及灵敏性. 


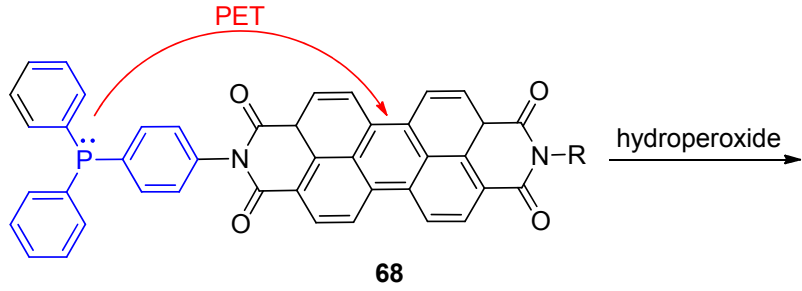

Low fluorescence

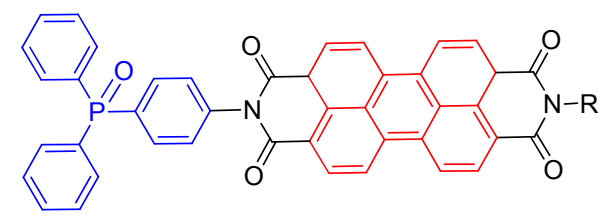

High fluorescence

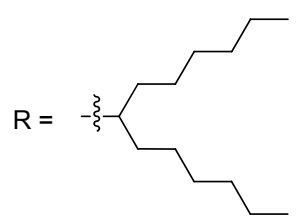

其他一些用于检测不同 ROS 的 PDIs 类探针也有报 道. 2009 年 Soh 等 ${ }^{[99}$ 报道了检测羟基自由基 $(\cdot \mathrm{OH})$ 的探 针 69. 该化合物荧光能在二甲基亚砜(DMSO)存在下随 着 $-\mathrm{OH}$ 浓度的增大而增强. 这是因为探针与 $\mathrm{DMSO}$ 和

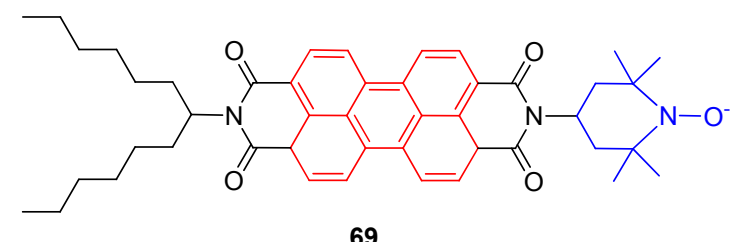

69

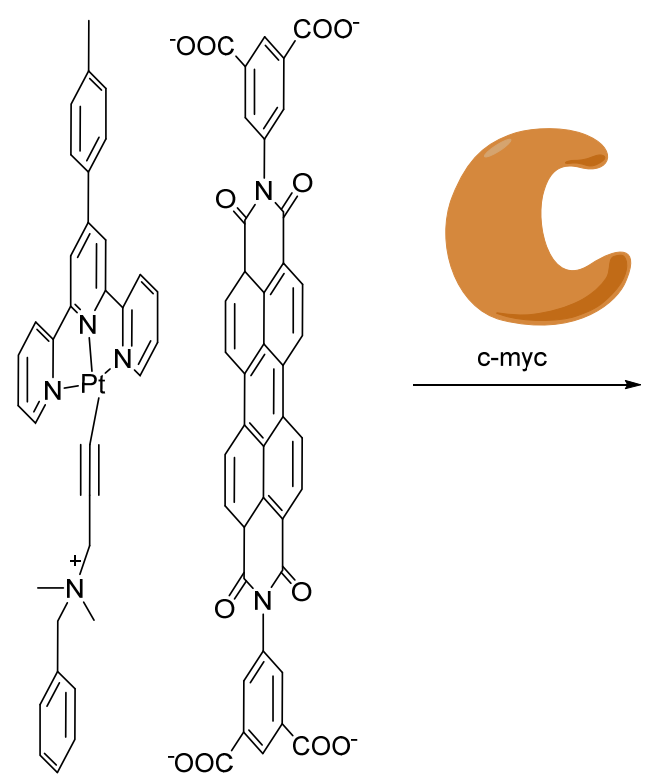

$\cdot \mathrm{OH}$ 反应生成氧负离子. 该探针对 $\cdot \mathrm{OH}$ 选择性好且灵 敏度高.

Kaloyanova 等 ${ }^{[100]}$ 设计合成了一种吸收和发射都大 于 $700 \mathrm{~nm}$ 的小分子近红外荧光探针 70. 该探针具有良 好的水溶性、高的摩尔消光系数和荧光量子效率. 该探 针实现了对线粒体的专一靶向检测并能够用于细胞内 线粒体的荧光成像. 这为研究线粒体以及线粒体在细胞 调亡等过程中的变化提供了很大的帮助.

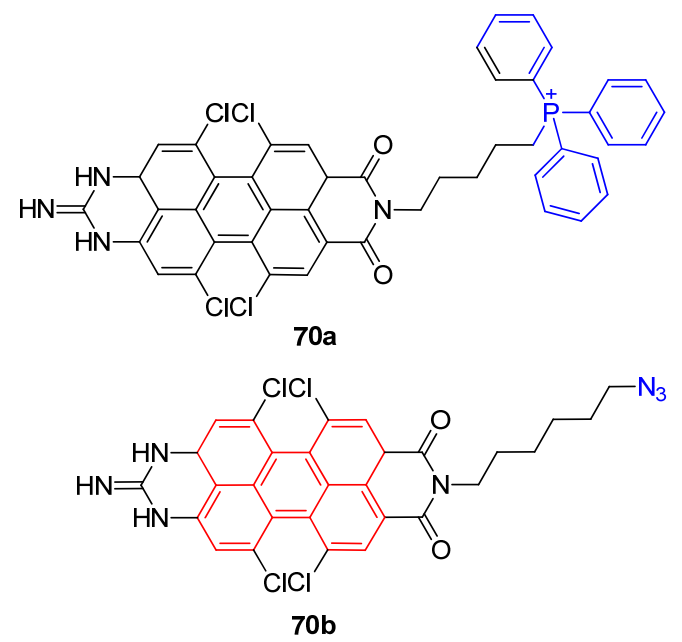

三联吡啶炔基铂配合物与 c-myc G-四链体具有很

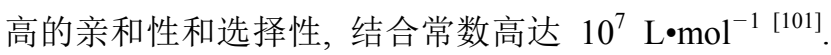
高云燕等 ${ }^{[102]}$ 通过三联吡啶铂与 PDIs 的 $\pi-\pi$ 堆积和静电 作用组装成超分子体系，构建了探针 71, 该探针可检测 c-myc G-四链体, 且表现出对 c-myc G-四链体较高的选 择性和较低的检测限(nmol) (Eq. 16).
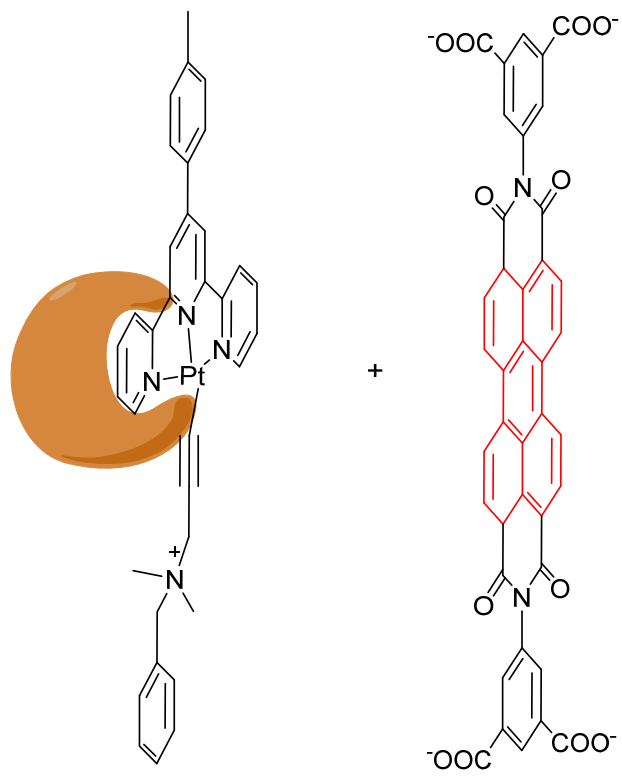


\section{4 结束语}

最近几年, PDIs 类苂光探针在离子检测、气体检测 及生物分子检测方面发展迅速, 对生物、医药和环境等 领域做出巨大贡献. 在这篇综述中, 我们探讨了近十年 来开发的以 PDIs 为苂光团母核并能成功应用于离子、 气体和生物分子检测的荧光探针, 并探讨了探针的设计 方法、响应机制和应用情况. 菲类衍生物具有易于合成, 可修饰位置多, 光、热、化学稳定性好等优点. 由于其 本身结构的关系, PDI 的疏水性较强, 导致较多的测试 是在有机体系内进行，限制了菲类衍生物在生物领域的 应用; 通过在酰亚胺的氮原子位置或湾位置引入阴离 子、阳离子或者非离子取代基进行修饰，使其在水中溶 解度得到大幅提升; 同时利用 PDIs 优异的光电性能和 其他技术如纳米技术结合起来, 扩大了在生物领域里的 应用，例如可实现蛋白、金属离子等特异性检测. PDIs 由于其自身的疏水性, 可以包裹一些疏水性的材料并通 过自组装等方式, 不断调控组装的形态, 成为生物成像 的材料. 虽然本文提到的探针中有一部分对待测物具有 高灵敏度和特异性, 但是我们仍需进一步研发与生物环 境、体内环境相容的新探针, 这一类探针的设计中我们 需要考虑到待测物浓度较低时的状态, 因此需要从化学 和生物两个方面来进行考虑: 化学方面我们需要找到更 多的反应机制(目前以聚集一解聚、络合为主); 生物方面 除了考虑高选择性和灵敏度之外, 还需要考虑高的光学 稳定性、低细胞毒性、良好的溶解度、细胞渗透性以及 生物环境物质的低干扰. 要想解决这些问题, 一般采用 以下方法: 一是将疏水的 PDIs 类荧光探针转化为亲水 材料，通常的做法是将其制备成水溶性的纳米颗粒，采 取物理性聚合物包裹或化学性共价键连接的方法将疏 水的苂光分子集中在核心，同时将亲水的聚合物包裹在 外围, 使整个纳米颗粒具有良好的水溶性; 二是利用聚 集 - 解聚, 使得荧光从猝灭变为苂光恢复, 这种方法得 到的纳米颗粒水溶性好并能够进行生物成像. 另一方 面, 对 PDIs 类衍生物进行化学修饰使其引入水溶性基 团，常用的修饰方法有两种：一种是在 PDIs 的湾位或酰 亚胺位引入带有正电荷的基团, 如季铵盐和磺酸盐等, 通过这种方法得到的水溶性 PDIs 分子可以与生物体中 常见的带电物质进行正负电荷相互作用, 从而得到苂光 的变化信号; 第二种方法是在 PDIs 上修饰带有不同生 物功能的水溶性基团, 如多肽链和寡糖等, 通过这种方 法得到的水溶性 PDIs 分子通常具有特殊的生物功能, 能够对某些生物分子进行特异性结合, 在提高生物相容 性的同时降低其细胞毒性. 综上所述, 在设计探针分子 时不仅要注意引入一些基团来提高或改变其水溶性, 还 需要考虑分子自身的生物相容性等开发其在生命科学
研究里的进一步的应用.

\section{References}

[1] Huang, C.; Barlow, S.; Marder, S. R. J. Org. Chem. 2011, 76, 2386.

[2] Jozeliunaite, A.; Striela, R.; Labanauskas, L.; Orentas, E. Synthesis 2017, 49, 5176.

[3] Pasaogullari, N.; Icil, H.; Demuth, M. Dyes Pigm. 2006, 69, 118.

[4] Gao, G.; Liang, N.; Geng, H.; Jiang, W.; Fu, H.; Feng, J.; Hou, J.; Feng, X.; Wang, Z. J. Am. Chem. Soc. 2017, 139, 15914.

[5] Wang, H.; Chen, L.; Xiao, Y. J. Mater. Chem. C 2017, 5, 12816.

[6] Liu, Y.; Cole, M. D.; Jiang, Y.; Kim, P. Y.; Nordlund, D.; Emrick, T.; Russell, T. P. Adv. Mater. 2018, 30, 1705976.

[7] Villafiorita-Monteleone, F.; Kozma, E.; Giovanella, U.; Catellani, M.; Paolino, M.; Collico, V.; Colombo, M.; Cappelli, A.; Botta, C. Dyes Pigm. 2018, 149, 331.

[8] Türkmen, G.; Erten-Ela, S.; Icli, S. Dyes Pigm. 2009, 83, 297.

[9] Wang, B.; Yu, C. Angew. Chem. 2010, 122, 1527.

[10] Wang, B.; Zhu, Q.; Liao, D.; Yu, C. J. Mater. Chem. 2011, 21, 4821.

[11] Wang, B.; Jiao, H.; Li, W.; Liao, D.; Wang, F.; Yu, C. Chem. Commun. 2011, 47, 10269.

[12] Würthner, F. Chem. Commun. 2004, 1564.

[13] Guo, X.; Zhang, D.; Zhu, D. Adv. Mater. 2004, 2, 125.

[14] Lin, J.; Zhu, C.; Liu, J.; Chen, B.; Zhang, Y.; Xue, J.; Liu, J. Chin. J. Chem. 2014, 32, 1116.

[15] Wang, H.; Wang, D.; Wang, Q.; Li, X.; Schalley, C. Org. Biomol. Chem. 2010, 8, 1017.

[16] Cheng, H.; Qian, Y. Dyes Pigm. 2015, 112, 317.

[17] He, X.; Liu, H.; Li, Y.; Wang, S.; Li, Y.; Wang, N.; Xiao, J.; Xu, X.; Zhu, D. Adv. Mater. 2005, 17, 2811.

[18] Feng, X.; An, Y.; Yao, Z.; Li, C.; Shi, G. ACS Appl. Mater. Interfaces 2012, 4, 614 .

[19] Zhong, L.; Xing, F.; Bai, Y.; Zhao, Y.; Zhu, S. Spectrochim. Acta, Part $A$ 2013, 115, 370.

[20] Wang, Y.; Zhang, L.; Zhang, G.; Wu, Y.; Wu, S.; Yu, J.; Wang, L. Tetrahedron Lett. 2014, 55, 3218.

[21] Fu, L.-N.; Qiao, Z. R.; Jin, X.; Li, L. R. Chem. Res. Appl. 2019, 31, 624 (in Chinese).

(付丽娜，乔振莣，金釒金，李林容，化学研究与应用， 2019，31, 624.)

[22] Che, Y.; Yang, X.; Zang, L. Chem. Commun. 2008, 1413.

[23] Ruan, Y.; Li, A.; Zhao, J.; Shen, J.; Jiang, Y. Chem. Commun. 2010 46, 4938.

[24] Fang, H.; Shellaiah, M.; Sinhg, A.; Raju Ramakrishnam, M. V.; Wu, Y.; Lin, H. Sens. Actuators, B 2014, 194, 229.

[25] Liu, K.; Xu, Z.; Yin, M.; Yang, W.; He, B.; Wei, W.; Shen, J. J. Mater. Chem. B 2014, 2, 2093.

[26] Han, A.; Liu, X.; Prestwich, G. D.; Zang, L. Sens. Actuators, B 2014, 198, 274.

[27] Malkongu, S.; Erdemir, S. Dyes Pigm. 2015, 113, 763.

[28] Erdemir, S.; Kocyigit, O.; Karakurt, S. Sens. Actuators, B 2015, $220,381$.

[29] Li, J.; Wu, Y.; Song, F.; Wei, G.; Cheng, Y.; Zhu, C. J. Mater. Chem. 2012, 22, 478 .

[30] Zhao, X.; Gong, L.; Wu, Y.; Zhang, X.; Xie, J. Talanta 2016, 149, 98.

[31] Zhou, R.; Li, B.; Wu, N.; Gao, G.; You, J.; Lan, J. Chem. Commun. 2011, 47, 6668.

[32] Wang, H.; Lang, Y.; Wang, H.; Lou, J.; Guo, H.; Li, X. Tetrahedron 2014, 70, 1997.

[33] Zhang, L.; Wang, Y.; Yu, J.; Zhang, G.; Cai, X.; Wu, Y.; Wang, L. Tetrahedron Lett. 2013, 54, 4019.

[34] Kumar, K.; Bhargava, G.; Kumar, S.; Singh, P. New J. Chem. 2018, $42,1010$.

[35] Singh, P.; Mittal, L. S.; Vanita, V.; Kumar, K.; Walia, A.; Bhargava, G.; Kumar, S. J. Mater. Chem. B 2016, 4, 3750.

[36] Malkondu, S. Tetrahedron 2014, 70, 5580. 
[37] Liu, X.; Zhang, N.; Zhou, J.; Chang, T.; Fang, C.; Shangguan, D. Analyst 2013, 138, 901.

[38] You, S.; Cai, Q.; Müillen, K.; Yang, W.; Yin, M. Chem. Commun. 2014, 50, 823 .

[39] Wan, S.; Zheng, Y.; Shen, J.; Yang, W.; Yin, M. ACS Appl. Mater. Interfaces 2014, 6, 19515

[40] Shen, Y.; Ma, X.; Zhang, B.; Zhou, Z.; Sun, Q.; Jin, E.; Sui, M.; Tang, J.; Wang, J.; Fan, M. Chem.-Eur. J. 2011, 17, 5319.

[41] Wu, Y.; Zhang, X.; Li, J.; Zhang, C.; Liang, H.; Mao, G.; Zhou, L.; Tan, W.; Yu, R. Anal. Chem. 2014, 86, 10389.

[42] Ling, J.; Naren, G.; Kelly, J.; Moody, T. S.; Prasanna de Silva, A. J. Am. Chem. Soc. 2015, 137, 3763.

[43] Huang, L.; Chang, T. S.-W. Chem. Commun. 2011, 47, 2291.

[44] Aigner, D.; Borisov, S. M.; Petritsch, P.; Klimant, I. Chem. Commun. 2013, 49, 2139.

[45] Aigner, D.; Freunberger, S. A.; Wilkening, M.; Saf, R.; Borisov, S. M.; Klimant, I. Anal. Chem. 2014, 86, 9293.

[46] Ma, Y.; Li, J.; Hou, S.; Zhang, J.; Shi, Z.; Jiang, T.; Wei, X. New J. Chem. 2016, 40, 6615.

[47] Ye, F.; Liang, X.; Wu, N.; Li, P.; Chai, Q.; Fu, Y. Spectrochim. Acta, Part $A$ 2019, 216, 359 .

[48] Georgiev, N. I.; Said, A. I.; Toshkova, R. A.; Tzoneva, D.; Bojinov, V. B, Dyes Pigm. 2019, 160, 28.

[49] Aigner, D.; Dmitriev, R. I.; Borisov, S. M.; Papkovsky, D. B.; Klimant, I. J. Mater. Chem. B 2014, 2, 6792.

[50] Zhang, W.; Gan, S. Y.; Li, F.; Han, D.; Zhang, Q.; Niu, L. RSC Adv. 2015, 5, 2207.

[51] Pacheco-Liňán, P.; Moral, M.; Nueda, M. L.; Cruz-Sánchez, R.; Fernández-Sainz, J.; Garzón-Ruiz, A.; Bravo, I.; Melguizo, M.; Laborda, J.; Albaladejo, J. Phys. Chem. C 2017, 121, 24786.

[52] You, S.; Cai, Q.; Müllen, K.; Yang, W.; Yin, M. Chem. Commun. 2014, 50, 823 .

[53] Roy, A.; Saha, T.; Talukdar, P. Tetrahedron Lett. 2015, 56, 4975.

[54] Cho, E. J.; Yeo, H. M.; Ryu, B. J.; Jeong, H. A.; Nam, K. C. Bull. Korean Chem. Soc. 2006, 27, 1967.

[55] Chen, Z.; Wang, L.; Zou, G.; Zhang, L.; Zhang, G.; Cai, X.; Teng, M. Dyes Pigm. 2012, 94, 410.

[56] Li, G.; Zhao, Y.; Li, J.; Cao, J.; Zhu, J.; Sun, X.; Zhang, Q. J. Org. Chem. 2015, 80, 196.

[57] Wang, R.; Li, J.; Li, G.; Hao, C.; Zhang, Y.; Wang, S.; Zhao, J.; Liu, Q.; Shi, Z. Dyes Pigm. 2018, 156, 225.

[58] Maiti, D. K.; Roy, S.; Datta, A.; Banerjee, A. Chem. Phys. Lett. 2013, 588,76

[59] Googson, F.; Panda, D.; Ray, S.; Mitra, A.; Guha, S.; Saha, S. Org. Biomol. Chem. 2013, 11, 4797.

[60] Du, F.; Bao, Y.; Liu, B.; Tian, J.; Li, Q.; Bai, R. Chem. Commun. 2013, 49, 4631.

[61] Gao, T.; Zhou, W.; Zhao, Y.; Chang, W.; Musendo, R.; Chen, E.; Song, Y.; Ren, X. Chem. Commun. 2019, 55, 3012.

[62] Sudhakar, P.; Neena, K.; Thilagar, P. Dalton Trans. 2019, 48, 7218.

[63] Fu, Y.; Tang, H.; Liu, Z.; Zhang, W. X.; Ren, J. Chin. J. Org. Chem. 2018, 38, 1806 (in Chinese). (付怡, 唐辉, 刘泽, 张万轩, 任君, 有机化学, 2018, 38, 1806.)

[64] Liu, Y.; Wang, K.; Guo, D.; Jiang, B. Adv. Funct. Mater. 2009, 19, 2230.

[65] Peng, H.; Ding, L.; Liu, T.; Chen, X.; Li, L.; Yin, S.; Fang, Y. Chem.-Asian J. 2012, 7, 1576.

[66] Zhang, J.; Liu, K.; Wang, G.; Shang, C.; Peng, H.; Liu, T.; Fang, Y. New J. Chem. 2018, 42, 12737.

[67] Hu, J.; Kuang, W.; Deng, K.; Zou, W.; Huang, Y.; Wei, Z.; Faul, C. F. J. Adv. Funct. Mater. 2012, 22, 4149.

[68] Deng, Q.; Zhou, E.; Huang, Y.; Qing, W.; Zhai, H.; Liu, Z.; Wei, Z. Chem. Commun. 2019, 55, 4379 .
[69] Ji, S.; Wang, H.; Wang, T.; Yan, D. Adv. Mater. 2013, 25, 1755.

[70] Kalita, A.; Hussain, S.; Malik, A. H.; Subbarao, N. V. V.; Iyer, P. K. J. Mater. Chem. C 2015, 3, 10767.

[71] Huang, Y.; Liu, X.; Wang, Q.; Fu, J.; Zhao, L.; Liu, Z.; Jin, D. J. Mater. Chem. C 2017, 5, 7644.

[72] Wang, J.; He, E.; Liu, X.; Yu, L.; Wang, H.; Zhang, H.; Zhang, H. Sens. Actuators, B 2017, 239, 898.

[73] Wang, K.; Yang, H.; Qian, X.; Xue, Z.; Li, Y.; Liu, H.; Li, Y. Dalton Trans. 2014, 43, 11542.

[74] Liu, X.; Zhai, H.; Zhang, S.; Fu, J.; Huang, Y. Sens. Actuators, B 2017, 243, 500 .

[75] Zhu, P.; Wang, Y.; Ma, P.; Li, S.; Fan, F.; Cui, K.; Ge, S.; Zhang, Y.; Yu, J. Anal. Chem. 2019, 91, 5591.

[76] Acikbas, Y.; Erdogan, M.; Capan, R.; Yukruk, F. Sens. Actuators, B 2014, 200, 61

[77] Sun, Q.; Lü, Y.; Liu, L.; Liu, K.; Miao, R.; Fang, Y. ACS Appl. Mater. Interfaces 2016, 8, 29128.

[78] Abdalla, M. A.; Bayer, J.; Rädler, J. O.; Müllen, K. Angew. Chem., Int. Ed. 2004, 43, 3967.

[79] Aubert, Y.; Asseline, U. Org. Biomol. Chem. 2004, 2, 3496.

[80] Rahe, N.; Rinn, C.; Carell, T. Chem. Commun. 2003, 2120.

[81] Bevers, S.; Schutte, S.; Mclaughlin, L. W. J. Am. Chem. Soc. 2000 $122,5905$.

[82] Zheng, Y.; Long, H.; Schatz, G. C.; Lewis, F. D. Chem. Commun. 2005, 4795.

[83] Wagner, C.; Wagenknecht, H.-A. Org Lett. 2006, 8, 4191.

[84] Wang, Y.; Chen, J.; Jiao, H.; Chen, Y.; Li, W.; Zhang, Q.; Yu, C. Chem.-Eur. J. 2013, 19, 12846.

[85] Chen, J.; Jiao, H.; Li, W.; Liao, D.; Zhou, H.; Yu, C. Chem.-Asian J. 2013, 8,276

[86] Chen, X.; Jou, M. J.; Yoon, J. Org. Lett. 2009, 11, 2181.

[87] Yan, L.; Ye, Z.; Peng, C.; Zhang, S. Tetrahedron 2012, 68, 2725.

[88] Li, Y.; Yin, S.; Hou, J.; Meng, L.; Gao, M.; Sun, Y.; Zhang, C.; Bai, S.; Ren, J.; Yu, C. Analyst 2019, 144, 2034.

[89] Wang, K.; An, H.; Rong, Z.; Cao, Z.; Li, X. Biosens. Bioelectron. 2014, 58, 27.

[90] Lin, Y.; Chapman, R.; Stevens, M. M. Anal. Chem. 2014, 86, 6410.

[91] D'Autréaux, B.; Toledano, M. B. J. Nat. Rev. Mol. Cell Biol. 2007, 8,813 .

[92] Weinstain, R.; Savariar, E. N.; Felsen, C N.; Tsien, R. Y. J. Am. Chem. Soc. 2014, 136, 874

[93] Sundaresan, M.; Yu, Z.; Finkel, T. Science 1995, 270, 296

[94] Ohshima, H.; Tatemichi, M.; Sawa, T. J. Arch. Biochem. Biophys. 2003, 417, 3

[95] Shah, A. M.; Channon, K. M. J. Heart 2004, 90, 486.

[96] Barnham, K. J.; Masters, C. L.; Bush, A. I. Nat. Rev. Drug Discovery 2004, 3, 205.

[97] Soh, N.; Ariyoshi, T.; Fukaminato, T.; Nakano, K.; Irie, M.; Imato, T. Bioorg. Med. Chem. Lett. 2006, 16, 2943.

[98] Soh, N.; Ariyoshi, T.; Fukaminato, T.; Nakajima, H.; Nakano, K.; Imato, T. Org. Biomol. Chem. 2007, 5, 3762.

[99] Maki, T.; Soh, N.; Fukaminato, T.; Nakajima, H.; Nakano, K.; Imato, T. Anal. Chim. Acta 2009, 639, 78

[100] Kaloyanova, S.; Zagraanyarski, Y.; Ritz, S.; Hanulová, M.; Koynov, K.; Vonderheit, A.; Müllen, K.; Peneva, K, J. Am. Chem. Soc. 2016, $138,2881$.

[101] Ou, Z.; Feng, Z.; Liu, G.; Chen, Y.; Gao, Y.; Li, Y.; Wang, X. Chem. Lett. 2015, 44, 425

[102] Gao, Y.-Y.; Cai, W. J.; Ou, Z. Z.; Ma, T. T.; Wang, Z. J.; Xu, M. H. Imaging Sci. Photochem. 2017, 35, 552 (in Chinese). (高云燕, 蔡温姣, 欧植泽, 马拖拖, 王子继, 许墨横, 影像科学 与光化学, 2017, 35, 552.) 